Verbist, M., Branco, J.M., Poletti, E., Descamps, T., Lourenço, P.B. (2018, accepted manuscript). Experimentations on the retrofitting of damaged Single Step Joints with Self-Tapping Screws. Materials and Structures. (doi.org/10.1617/s11527-018-1234-8)

The final publication is available at link.springer.com:

https://link.springer.com/article/10.1617/s11527-018-1234-8

\title{
Experimentations on the retrofitting of damaged Single Step Joints with Self-Tapping Screws
}

Maxime Verbist ${ }^{a}$, Jorge M. Branco ${ }^{a}{ }^{*}$, Elisa Poletti ${ }^{a}$, Thierry Descamps ${ }^{b}$, Paulo B. Lourenço ${ }^{a}$

a ISISE, Department of Civil Engineering, University of Minho, Portugal

${ }^{\mathrm{b}}$ Department of Architectural Engineering, University of Mons, Belgium

* Corresponding author:

ISISE, Department of Civil Engineering, University of Minho,

Campus de Azurém, 4800-058, Guimarães, Portugal

e-mail: jbranco@civil.uminho.pt

Tel: +351 253510200; Fax: +351253510217

e-mail addresses: Maxime Verbist - verbist.maxime@hotmail.com

Jorge M. Branco - jbranco@civil.uminho.pt

Elisa Poletti - elisapoletti@gmail.com

Thierry Descamps - Thierry.DESCAMPS@umons.ac.be

Paulo B. Lourenço - pbl@civil.uminho.pt 


\section{Abstract}

When assessing the roof of existing buildings, engineers may be confronted with structural joints badly preserved, for instance the damaged Single Step Joint (SSJ) located at the foot of timber trusses. Since the early appearance of failure modes in this traditional carpentry connection may lead to the collapse of the whole timber truss, the retrofitting of damaged SSJ is then required as an economically-viable intervention to stabilize the roof structure. In consequence, the retrofitting of damaged SSJ with Self-Tapping Screws (STS) has been conducted through the Experimental Campaign in order to explore further different possibilities offered by this recent intervention technique (Sobra et al. (2016)). To this end, two strategies, noted R1 and R2, have been proposed to retrofit the SSJ specimens with STS, which had been previously damaged due to both failure modes, namely the crushing at the front-notch surface and the shear crack in the tie beam (Verbist et al. (2017)). Afterwards, the SSJ specimens retrofitted with STS have been tested under monotonic compression in the rafter in order to pull out their mechanical behaviour encompassing the failure modes, the force-displacement response, the stiffness of the connection, and the ultimate normal force in the rafter. By comparing the mechanical behaviour of retrofitted SSJ specimens with the initial ones from Verbist et al. (2017), the performances of both retrofitting strategies with STS have been discussed. Furthermore, the impact of the shear row splitting on the mechanical behaviour of retrofitted SSJ has been evaluated, by providing some warnings to engineers when intervening in existing timber trusses featuring natural damage such as the shrinkage splitting.

\section{Keywords}

Timber; Single Step Joint; Retrofitting; Self-Tapping Screws; Experimentation 


\section{Introduction}

When assessing the roof of existing buildings, engineers may be confronted with timber trusses badly preserved, comprising damaged elements and/or joints. According to Valentin (2009), two main groups of damage may occur in the service life of timber trusses: natural and structural damage. Because they are conditioned by different environmental factors within the building envelope (e.g. ambient temperature, air relative humidity, moisture content...), natural damage stand for the wood deterioration due to the presence of biological, chemical and/or physical agents. Since Step Joints are traditional carpentry connections located at the foot of timber trusses, they are often exposed to recurrent humidity at the tie beam end in contact with wet masonry walls. As the most common Step Joint encountered on-site (Yeomans (2003)), the Single Step Joint (SSJ) may be subject to natural damage, such as timber shrinkage splitting, fungal decay or insect attacks (Teles et al. (2001), Shupe et al. (2008)), resulting in undermining severely the mechanical behaviour of the connection with the rushed appearance of failure modes. By opposition, structural damage are the result of a poor design at the global level of the whole carpentry or at the local level inside elements and joints. Because the loading conditions have been modified over several restoration stages in their service life, timber trusses may not work as efficiently as expected from their initial design, which leads to the emergence of failure modes threatening the structure integrity. In the case study of the SSJ, structural damage can be triggered by both failure modes (Verbist et al. (2017)): the crushing at the front-notch surface, and the shear crack in the tie beam.

In order to hold steady damaged SSJ within timber trusses, the repair and/or retrofitting as on-site interventions are then required. The repair of damaged timber elements and connections consists in gaining back their initial mechanical behaviour (i.e. stiffness, load-bearing capacity, and force-displacement response) before the damage appearance. 
Because this laborious intervention is only used for highly deteriorated timber structures as extreme case study (e.g. severe fungal decay of wood), the repair has been left out in the present research, by more focusing on the retrofitting techniques when dealing with structural damage. Similar to the repair, the retrofitting aims at stabilizing damaged timber elements and joints, but does not guarantee the regain of their initial mechanical behaviour. On the other hand, the reinforcement should be stated as a different intervention which implies strengthening sound timber elements or joints in order to enhance their initial mechanical behaviour.

From the scientific literature (Yeomans (2003), Branco et al. (2015) and Tampone et al. (2016)), different techniques exist in order to intervene in existing timber trusses, since their use conditions mostly depend on the type and extent of damage inside timber elements or connections. With well-advanced development of fungal decay, severely damaged SSJ are cut and replaced by prosthesis from sound timber elements linked with resin as repair technique (Descamps et al. (2016)). As regards structural damage entailing the SSJ destabilization, several metal devices (e.g. stirrup, lateral bolts, binding strip, tension ties) have been used over time like traditional reinforcement and retrofitting techniques (Parisi et al. (2000)). As principles restoration (Yeomans et al.(2003), Croatto et al. (2014)), the reversibility and compatibility of intervention techniques chosen must be ensured to preserve the integrity of timber structure on-site. In other words, intervention techniques should cause as little damage as possible and not taint the initial mechanical behaviour of timber elements and connections.

Conform with experimental works (Görlacher et al. (1991), Munafò et al. (2015) and Verbist et al. (2017)), the SSJ can be damaged due to both failure modes: the crushing at the front-notch surface, and the shear crack in the tie beam. While the former generates high deformation inside the traditional carpentry connection, the latter causes the collapse of the whole timber truss. Therefore, the damaged SSJ have to be retrofitted with Self-Tapping Screws (STS) since the efficiency and attractiveness of this modern 
technique has recently stood out in timber engineering. According to Sobra et al. (2016), several reinforcement strategies with STS have been investigated through experimentations under monotonic compression tests in order to prevent the emergence of both failure modes in sound SSJ specimens. By comparing the mechanical behaviour from unreinforced SSJ specimens with that from strengthened ones with STS, the authors (Sobra et al. (2016) showed that the initial load-bearing capacity of the connection could be reached whereas the obtained stiffness dropped. Since the initial stiffness cannot be regained for the reinforcement, the intervention technique with STS should only be used to retrofit damaged timber elements and joints. Although the STS are intensively used as metallic fasteners in timber-to-timber connections in new building constructions (Blass et al. (2002), Tomasi et al. (2010), Bléron et al. (2015), Dietsch et al. (2015)), there is still a huge lack of knowledge about the strategies of STS positioning and about the retrofitting performance with STS when dealing with damaged timber structures on-site. In order to fulfil gaps from the literature, the present research aims at determining the efficient retrofitting strategies with STS for the SSJ previously damaged due to both failure modes. To this end, the Experimental Campaign on the retrofitting of damaged SSJ with STS has been carried on into several investigation steps. First of all, two retrofitting strategies with STS have been proposed for the SSJ damaged due to the crushing and the shear crack, by taking into account the restoration principles in existing timber structures (Yeomans (2003), Croatto et al. (2014)) and the mechanical performances of STS inside timber-totimber connections in single shear (Blass et al. (2002), Tomasi et al. (2010), Bléron et al. (2015), Dietsch et al. (2015)). Afterwards, several damaged SSJ specimens from Verbist et al. (2017) have been retrofitted with STS as per two strategies previously defined. Last but not least, the retrofitted SSJ specimens have been tested under monotonic compression in the rafter to pull out their mechanical behaviour (i.e. failure modes, ultimate force, stiffness, and force-displacement response). Based on these experimental 
results, the performance of two retrofitting strategies with STS has been discussed for the damaged SSJ.

\section{Experimetal Campaign}

The Experimental Campaign firstly aims at determining two retrofitting strategies with SelfTapping Screws (STS) for Single Step Joint (SSJ) specimens damaged due to the crushing at the front-notch surface, and the shear crack in the tie beam (Verbist et al. (2017)). Before focusing on the mechanical behaviour of retrofitted SSJ specimens, different geometrical configurations and related mechanical performances of STS must properly be understood in timber-to-timber connections. Meanwhile, a good compromise on the retrofitting strategies has to be reached in order to conciliate the mechanical performances and the restoration principles (Yeomans (2003), Croatto et al. (2014)) such as: the workability on-site, the reduced visual impact and the reversibility of the intervention technique. The next step of the Experimental Campaign consists of carrying out 26 SSJ specimens retrofitted with STS, as

per two strategies thus defined, under monotonic compression in the rafter, in order to determine their mechanical behaviour (i.e. failure modes, ultimate force, stiffness, and force-displacement response).

\subsection{Materials}

\subsubsection{Single Step Joint specimens}

From the work of Verbist et al. (2017), the Single Step Joint (SSJ) under monotonic compression in the rafter can be damaged due to both failure modes illustrated in Figure 1: the crushing at the front-notch surface, and the shear crack at the heel depth along the shear length in the tie beam. The emergence of both failure modes and the related loadbearing capacities are highly conditioned by the SSJ geometrical parameters: i) the rafter skew angle $\beta_{\text {rafter }}$ ii) the inclination angle of the front-notch surface $\alpha_{\text {front }}$ to the normal 
of the tie beam grain; iii) the geometrical proportion between the shear length and the heel depth $l_{v} / t_{v}$.

In the previous Experimental Campaign (Verbist et al. (2017)), two repetitive tests for 13 different SSJ geometrical configurations, or 26 sound SSJ specimens in total, had been performed under monotonic compression in the rafter, by modifying three geometrical parameters previously quoted. As detailed in Table 1, two values of the rafter skew angle $\beta_{\text {rafter }}$ had been chosen: i) $30^{\circ}$ for 20 SSJ specimens; ii) $45^{\circ}$ for the other six ones. Besides, the geometrical parameter $\alpha_{\text {front }}$ varies according to the three different SSJ families: the Geometrical Configuration Ideal Design (GCID) with $\alpha_{\text {front }}=\beta_{\text {rafter }} / 2$, the Geometrical Configuration Perpendicular to the Rafter (GCPR) with $\alpha_{\text {front }}=\beta_{\text {rafter }}$, and the Geometrical Configuration Perpendicular to the Tie Beam (GCPTB) with $\alpha_{\text {front }}=0^{\circ}$. Regarding the geometrical proportion $l_{v} / t_{v}$ between the shear length and heel depth, four ratios had been chosen for 20 SSJ specimens characterized by $\beta_{\text {rafter }}=30^{\circ}: 240 / 25,240 / 30,240 / 40$, and $160 / 30[\mathrm{~mm} / \mathrm{mm}]$. For the other six ones featuring $\beta_{\text {rafter }}=45^{\circ}$, the geometrical parameter $l_{v} / t_{v}$ had been settled to the ratio $240 / 30[\mathrm{~mm} / \mathrm{mm}]$. Furthermore, the cross-section dimensions of timber SSJ elements are $100 \times 100 \mathrm{~mm}$ for the rafter, and $100 \times 160 \mathrm{~mm}$ for the tie beam respectively.

These SSJ specimens made of Pinus sylvestris have been sorted out in the present Experimental Campaign as per their structural damage, namely into two main failure modes. The Table 1 informs about it, that 12 SSJ specimens were damaged due to the crushing at the front-notch surface while the 14 other ones failed due to the shear crack along the shear length at the heel depth in the tie beam. The classification of damaged SSJ specimens in respect with both failure modes is crucial for the establishment of different retrofitting strategies with Self-Tapping Screws in the next steps of the Experimental Campaign. 


\subsubsection{Self-Tapping Screws}

Among the intervention techniques used for the reinforcement and retrofitting of timber connections, Self-Tapping Screws (STS) have recently stood out from others in the field of timber engineering by their easy handling on-site, their low cost, their reduced visual impact, their easy visual inspection and their high degree of reversibility. As a reminder, an intervention technique is reversible if three conditions below are met (Yeomans (2003), Croatto et al. (2014)):

- The intervention technique over its lifetime (i.e. handling, action time and removal) causes as little damage as possible inside structural elements or joints.

- The intervention technique can easily be removed from the structure, facilitating future recoveries and other intervention strategies.

- The removal of the intervention technique enables to get back to the original state (i.e. mechanical behaviour) of structural elements or joints non-retrofitted.

Because wood is an orthotropic material featured by low tensile, compressive strength perpendicular to the grain as well as low shear strength parallel to the grain, timber elements and connections must be reinforced with STS in order to enhance their mechanical properties (Dietsch et al. (2015), Bléron et al. (2015)). Thanks to their fully or partially threaded shank, these screws provide to the timber joint elements: lateral shear strength, high tensile strength, and withdrawal strength. Moreover, the reinforcement with STS may induce a ductile failure mode inside the timber-to-timber connection according to Tomasi et al. (2010), by preventing the emergence of brittle failures such as the tensile crack perpendicular to the grain or shear crack parallel to the grain. Nevertheless, the stiffness of the joint reinforced with STS may have been changed too. For instance, Sobra et al. (2016) reported that the tested reinforcement strategies with STS, for one SSJ geometrical configuration against the crushing at the front-notch surface, could lead to decreasing significantly the stiffness while reaching the initial load-bearing capacity of the connection. In that context, STS have then been used as innovative intervention technique in the present 
Experimental Campaign to retrofit SSJ specimens damaged due to the crushing at the frontnotch surface, and the shear crack in the tie beam.

Different STS typologies exist, since they are featured by their own geometry (i.e. tip, head shape, and thread length), mechanical performances, and specific implementation within timber structures. As illustrated in Figure 2, two STS typologies are commonly used in timber engineering: FTS (Fully Threaded Screws), and PTS (Partly Threaded Screws). Because FTS provide higher axial strengths $\left(R_{a x, \alpha}\right)$ than lateral ones $\left(R_{\text {lat }, \alpha}\right)$ due to their complete thread length, those screws are then positioned under an inclination angle $\alpha$ to the shear plane of tensile-shear timber-to-timber connections. Beside of ductile failures, this implementation could nevertheless entail brittle failure modes: either the FTS pull-out at the interface of timber joint elements with the threaded shank, or the tensile failure of the screws crosssection. On the other hand, the second STS typology stated as PTS are characterized by their half-length threaded shank, by providing a significant lateral strength $\left(R_{\text {lat }, \alpha}\right)$ for shear timber-to-timber connections. Therefore, PTS are positioned perpendicularly to the shear plane in order to bear the shear loading $\left(R_{V}\right)$ only. In addition to their easy-friendly implementation on-site, PTS may lead to ductile failure modes such as the plastic hinge of screws.

Since both screws typologies are called "self-tapping", the specific shape of the tip and the partly/fully threaded shank make easier their implementation and maintenance over time inside timber joint elements, by using only a screwdriver as work tool. Furthermore, the predrilled holes and good spacing between screws (Eurocode 5 (2004), ETA-11/0030 (2012), Uibel et al. (2010)) ensure an accurate STS implementation, by reducing the appearance risk of shear row splitting inside timber joint elements at the headside screw. Meanwhile, the pre-drilling inside timber connections is required if at least one of both following conditions is met (Eurocode 5 (2004)): i) the characteristic wood density is greater than $500 \mathrm{~kg} / \mathrm{m}^{3}$; ii) the screw diameter exceeds $6 \mathrm{~mm}$. 


\subsection{Single Step Joints retrofitted with STS}

Based on the mechanical performances of Self-Tapping Screws (STS) and the restoration principles, two retrofitting strategies with STS have then been established for the Single Step Joint (SSJ) damaged due to the crushing at the front-notch surface and the shear crack in the tie beam. As illustrated in Figures 3 and 4 , the minimum distance and spacing of STS $\left(a_{1},, a_{2}\right.$, $\left.a_{3, c}, a_{3, t}, a_{4}\right)$ as per two retrofitting strategies can be given by Eurocode 5 (2004), the recommendations from Uibel et al. (2010), or by the European Technical Approval ETA11/0030 (2012).

\subsubsection{Retrofitting strategy against the crushing}

The crushing at the front-notch surface is a ductile failure mode causing serious deformation of the SSJ, according to Verbist et al. (2017). In order to diminish the rafter thrust and the related crushing at the front-notch surface, the normal load in the rafter $\left(N_{\text {rafter, } R}\right)$ has to be transferred mainly at the bottom-notch surface from the rafter to the tie beam. To this end, the first retrofitting strategy labelled R1, for the SSJ damaged due to the crushing, consists in positioning the Fully Threaded Screws (FTS) perpendicularly to the rafter edge at the bottom-notch surface as illustrated in Figure 3. Because they are inclined under an angle $\alpha$ to the normal of the bottom-notch surface, FTS can bear the tensile component from the rafter thrust with their withdrawal capacity $\left(R_{a x, \alpha}\right)$, and the shear component with their lateral strength $\left(R_{\text {lat }, \alpha}\right)$. In consequence, the load-bearing capacity $\left(R_{V, b o t t}\right)$ parallel to the bottom-notch surface is ensured by the FTS implementation in the rafter.

Even if most of the internal forces go from the rafter to the tie beam through FTS at the bottom-notch surface, the front-notch surface may still be subject to a significant part of the rafter thrust. Therefore, the compressive strength at the front-notch surface may be taken into account when estimating the rafter load-bearing capacity $\left(N_{\text {rafterR }}\right)$ for the retrofitted SSJ with STS. Since the shear crack occurs as the final failure mode in the SSJ (Verbist et al. (2017)), the shear strength along the shear length $l_{v}$ parallel to the grain, at the heel depth 
$t_{v}$ in the tie beam, may also be considered. Whatever the failure mode noticed, the retrofitting strategy R1 should then provide higher rafter load-bearing capacities than the initial ones from sound SSJ specimens before the crushing appearance.

As the upper side of the rafter is hidden by the roof covering, there is no visual impact of the retrofitting with STS on the existing timber structure. Meanwhile, the retrofitting strategy R1 beforehand requires the partial roof disassembly to make easier the accessibility to the SSJ when implementing FTS in the rafter. Due to the specific geometry of the SSJ heel, the rafter end characterized by a small thickness remains brittle. Therefore, the workers must pay attention not to position the screws too close to the front-notch surface in order to prevent timber row splitting in the rafter. Furthermore, the Table 2 and Figure 3 detail the STS implementation (i.e. distance, spacing, type and amount) for the retrofitting of 12 SSJ specimens damaged due to the crushing, as per the strategy R1. It should be noted that FTS are characterized by $9 \mathrm{~mm}$ diameter and $200 \mathrm{~mm}$ length.

\subsubsection{Retrofitting strategy against the shear crack}

When the shear crack occurs in the SSJ, the tie beam splits into two parts at the heel depth $t_{v}$ along the shear length $l_{v}$ parallel to the grain. As a result, the upper part of the tie beam can freely move, leading to the collapse of the rafter and of the whole timber truss (Munafò et al. (2015) and Verbist et al. (2017)). Before retrofitting the damaged connection, engineers must reposition properly the upper part of the tie beam and the rafter in order to stabilize the timber truss as suggested Valentin (2009). As soon as both timber elements are hold steady, the second retrofitting strategy with STS labelled R2, for the SSJ damaged due to the shear crack, can be performed in order to prevent the free movement of the upper part of the tie beam along the shear plane.

As shown in Figure 4, the second retrofitting strategy (R2) against the shear crack consists of implementing two STS typologies inside the SSJ: Fully Threaded Screws (FTS), and Partly Threaded Screws (PTS). Since they can bear tensile and shear components from the rafter thrust due to their complete thread of the shank, FTS are positioned perpendicularly to the 
rafter edge at the bottom-notch surface, similarly to the first retrofitting strategy (R1). On the other hand, PTS are drilled perpendicularly to the grain from the upper part to bottom part of the tie beam, so that those screws only counteract lateral loadings directly from the rafter thrust. The tie beam and rafter retrofitted with STS then work together in order to counteract the rafter thrust inside the Single Step Joint. In contrast to the first retrofitting strategy (R1), the rafter load-bearing capacities $\left(N_{\text {rafterR }}\right)$ for the second retrofitting strategy (R2) may not reach the initial ones from sound SSJ specimens before the shear crack appearance.

Since the bottom side of the tie beam is supported by the masonry wall, this area is not directly accessible for the intervention techniques, without removing out the tie beam from the timber truss. Therefore, the retrofitting strategy R2 with STS is focused on the upper side of the tie beam and rafter, although the partial roof disassembly is still required for an easy accessibility to the SSJ. The Table 3 and Figure 4 give the STS implementation (i.e. distance, spacing, type and amount) for the retrofitting of 14 SSJ specimens damaged due to the shear crack, as per the strategy R2. Furthermore, FTS are characterized by $9 \mathrm{~mm}$ diameter and 200 $\mathrm{mm}$ length whereas PTS are featured by $8 \mathrm{~mm}$ diameter and $140 \mathrm{~mm}$ length.

\subsection{Monotonic compression tests}

In order to simplify the experimental process and setup of the tests, only the permanent and long-term loads on the roof have been considered in the present Experimental Campaign. In consequence, monotonic compression tests have been carried out on the SSJ specimens retrofitted with STS as per both strategies R1 and R2 to pull out their mechanical behaviour (i.e. failure modes, ultimate force, stiffness, and force-displacement response). Similar to Verbist et al. (2017), the monotonic compression test consists in applying a vertical force parallel to the grain at the top of the rafter, noted $N_{\text {rafter }}$, as shown in Figure 5.

The setup inclination on which the tie beam stands must be checked according to the rafter skew angles $\beta_{\text {rafter, }}$, namely 30 and $45^{\circ}$, for each SSJ geometrical configuration. Whereas the 
rafter bears the compression parallel to the grain within timber trusses under loads, the tie beam has to counteract tensile stress parallel to the grain due to the rafter thrust. As illustrated in Figure 5, the tie beam is simply supported with free end in front of the SSJ heel while the opposite end at the back side of the connection is anchored, leading to stretching the tie beam parallel to the grain when loading the rafter in compression from the actuator. Besides, two LVDT's aided by the grid were used to measure the displacements of the frontnotch and bottom-notch surfaces at both sides of the SSJ retrofitted with STS. Moreover, one LVDT has been implemented under the shear crack to assess the movement of the upper side of the tie beam parallel to the grain. The loading velocity has been kept between 0.01 and $0.03 \mathrm{~mm} / \mathrm{s}$ during all the experiments.

\section{Results and Discussion}

After performing several monotonic compression tests in the rafter, the experimental results on the mechanical behaviour of Single Step Joint (SSJ) specimens retrofitted with SelfTapping Screws (STS) as per two strategies previously defined have been collected, by focusing more on the ultimate force, stiffness, force-displacement response, and failure modes. By comparing the mechanical behaviour between the sound SSJ specimens and the retrofitted ones with STS, the performance of both retrofitting strategies has then been discussed in respect with the initial failure modes, namely the crushing at the front-notch surface, and the shear crack in the tie beam.

\subsection{Mechanical behaviour of retrofitted Single Step Joints}

\subsubsection{Ultimate force, stiffness and force-displacement response}

From the present Experimental Campaign, the collected results on the Single Step Joint (SSJ) specimens retrofitted with Self-Tapping Screws (STS) are gathered into two strategies: the SSJ retrofitting against the crushing at the front-notch surface (R1), and the SSJ retrofitting 
against the shear crack in the tie beam (R2). As detailed in Table 4, experimental values of the ultimate normal forces in the rafter and of the stiffness at the front-notch surface, for the initial SSJ specimens and retrofitted ones $\left(_{R}\right)$ with STS, are respectively noted: $N_{\text {rafter }}$, $\mathrm{N}_{\text {rafterR }}, K_{F N}$ and $K_{F N, R}$. The coefficients $\Delta_{\text {rel }, N}=100 .\left(N_{\text {rafter } R}-N_{\text {rafter }}\right) / N_{\text {rafter }}[\%]$ and $\Delta_{\text {rel,K}}=100 .\left(K_{F N, R}-K_{F N}\right) / K_{F N}$ [\%] are respectively the relative variation of the ultimate normal forces in the rafter and the relative variation of the stiffness at the front-notch surface, between the initial SSJ specimens and the retrofitted ones with STS.

As regards the first strategy (R1) given in Table 4, the ultimate normal forces in the rafter from the SSJ specimens retrofitted with STS are from 11 to $141 \%$ superior to the ultimate normal forces in the rafter from the initial SSJ specimens tested. However, the stiffness from the retrofitted SSJ specimens is from 38 to $86 \%$ inferior to the stiffness from the initial SSJ specimens. By comparing the retrofitted SSJ specimens, it seems that both the inclination angle $\alpha_{\text {front }}$ of the front-notch surface and the geometrical proportion $l_{v} / t_{v}$ between the shear length and heel depth do not significantly influence the ultimate force in the rafter. On the other hand, the latter highly depends on the rafter skew angle $\beta_{\text {rafter }}$ and above all on the amount of Full Threaded Screws (FTS) implemented in the rafter. It is then obvious that positioning a greater amount of FTS in the rafter, which can be for low rafter skew angles $\beta_{\text {rafter }} \leq 30^{\circ}$, will provide higher strength to the retrofitted SSJ specimens.

The force-displacement responses shown in Figure 6 have been plotted for three initial SSJ specimens and three retrofitted ones with STS as per the first strategy (R1). The geometrical configurations of six SSJ specimens are characterized by a rafter skew angle $\beta_{\text {rafter }}=45^{\circ}$ and a geometrical proportion between the shear length and heel depth $l_{v} / t_{v}=240 / 30[\mathrm{~mm} / \mathrm{mm}]$. Contrarily to the initial SSJ specimens, the force-displacement responses from the retrofitted SSJ specimens are quite similar, and do not depend on the inclination angle $\alpha_{\text {front }}$ of the front-notch surface. Besides, they feature a linear compressive deformation at the frontnotch surface until reaching the ultimate normal force in the rafter. 
At this point, the post-peak response, illustrated in Figure 6 (GCPTB_45 ${ }^{\circ}$ tv30_240SL_1_R1), is usually equated to a plateau, due to the yielding of the FTS implemented in the rafter. Nevertheless, the normal force in the rafter may slightly decrease according to high displacement of the front-notch surface (GCPR_45 $5_{-} t v 30 \_240 S L_{-} 2$ _R1), when the shear row splitting appears in the rafter after reaching the ultimate force. In the case where the shear row splitting occurs earlier (GCID_45 $5_{-}$tv30_240SL_1_R1), the normal force in the rafter still keeps rising but slowly, as long as the yielding of FTS has not started yet. In other cases, the shear crack may emerge in the tie beam as the final failure mode (GCPR_45 _tv30_240SL_2_R1 and GCPTB_45 $5_{-}$tv30_240SL_1_R1), resulting in the drop of the normal force in the rafter after reaching the ultimate value. Concerning the second strategy (R2) detailed in Table 4, the ultimate normal forces in the rafter from the SSJ specimens retrofitted with STS can be up to $91 \%$ higher than the ultimate normal forces in the rafter from the initial SSJ specimens tested. For two retrofitted SSJ specimens (i.e. GCPR_30 _tv30_160SL_2_R2 and GCPR_30 _tv30_240SL_2_R2), they however decrease up to 5 and $16 \%$ respectively from their initial values. Besides, the stiffness from all the retrofitted SSJ specimens as per the second strategy (R2) is from 35 to $88 \%$ inferior to the stiffness from the initial ones. Since the shear row splitting may occur before the yielding of STS in the tie beam and rafter, a significant variation of the ultimate normal forces in the rafter can be obtained for a same SSJ geometrical configuration, which makes very difficult to establish strong relationships with the SSJ geometrical parameters. From the retrofitted SSJ specimens featured by the rafter skew angle $\beta_{\text {rafter }}=30^{\circ}$, the ultimate normal forces in the rafter can nonetheless be influenced by the shear length $l_{v}$ and thus by the amount of Partly Threaded Screws (PTS) implemented in the tie beam. Higher the shear length and amount of PTS, higher the ultimate force in the rafter.

As shown in Figure 7, the force-displacement responses are to reflect three initial SSJ specimens and three retrofitted ones with STS as per the second strategy (R2). The geometrical configurations of six SSJ specimens are characterized by a rafter skew angle 
$\beta_{\text {rafter }}=30^{\circ}$ and a geometrical proportion between the shear length and heel depth $l_{v} / t_{v}=160 / 30[\mathrm{~mm} / \mathrm{mm}]$. Although they feature a linear compressive deformation at the front-notch surface until reaching the ultimate normal force in the rafter, the respective force-displacement responses are slightly different, due to the emergence conditions of shear row splitting inside timber joint elements. For instance, the shear row splitting in the tie beam occurs earlier for the specimen GCPTB_30 $0_{-}$tv30_160SL_1_R2, causing a slowdown in increasing the normal load in the rafter as well as a significant reduction of the ultimate force. When yielding the FTS in the rafter, the post-peak response is featured by a plateau, but it may go down with the quick appearance and development of shear row splitting in the rafter (GCID_30 _tv30_160SL_2_R2). Being characterized by a similar post-peak response, the third retrofitted SSJ specimen $\left(G C P R \_30^{\circ}\right.$ tv30_160SL_2_R2) is quite particular, featuring a lower ultimate force in the rafter and a lower stiffness than those from the other two ones. These results come from a bad implementation of PTS in the tie beam, triggering the early emergence of partial shear row splitting in the timber element long before the monotonic compression test has started.

Through modifying the geometrical proportions between the shear length and heel depth $l_{v} / t_{v}$, six force-displacement responses are plotted in Figure 8 for three initial SSJ specimens and three retrofitted ones with STS as per the second strategy (R2). The SSJ geometrical configurations are then characterized by three values of the geometrical parameter $l_{v} / t_{v}$ : $240 / 25,240 / 40$, and $160 / 30[\mathrm{~mm} / \mathrm{mm}]$. The force-displacement responses of those three retrofitted SSJ specimens can be interpreted in the same way than the previous ones shown in the Figure 7, based on the concomitance mechanism between the shear row splitting and the yielding of STS in both timber joint elements. Although their respective stiffness are equivalent, the ultimate forces in the rafter significantly vary according to the heel depth $t_{v}$, namely the thickness of the upper part of the tie beam (Figure 4). When considering the same amount of PTS screws (or same shear length $l_{v}$ ) in the tie beam, the ultimate force in the rafter illustrated in Figure 8 is higher for $t_{v}=25 \mathrm{~mm}$ than that for $t_{v}=40 \mathrm{~mm}$. This 
phenomenon can be related to the "rope effect", which consists of increasing the friction forces on the shear plane, and thus the load-bearing capacity of the joint, by pulling the timber members together when yielding the STS. Although this type of friction forces should rise with the thickness of the timber connection member at the headside of screws (Eurocode 5 (2004), Blass et al. (2002), ETA-11/0030 (2012)), the "rope effect" is still notable for very low heel depth $t_{v} \leq 25 \mathrm{~mm}$, thanks to the countersunk flat head of PTS which tightens further the upper and bottom parts of the tie beam together during the yielding step. In addition, the "rope effect" stunts the emergence and development of shear row splitting in the tie beam.

\subsubsection{Failure modes}

From the tested specimens of Single Step Joint (SSJ) retrofitted with Self-Tapping Screws (STS) as per both strategies R1 and R2, different failure modes have been noticed during the Experimental Campaign and then classified into two groups as detailed in Table 5: i) Overall failure modes of the retrofitted SSJ specimens; ii) Local failure modes of STS implemented inside the tie beam and rafter. The former group encompasses both failure modes from the SSJ, namely the crushing at the front-notch surface and the shear crack in the tie beam, plus the shear row splitting in the retrofitted rafter and tie beam at the headside of screws. The latter group includes different failure modes of timber-to-timber connections in single shear with metallic fasteners provided by Eurocode 5 (2004), such as the crushing inside timber joint members due to the STS embedment, the single or double plastic hinges of STS. It should be mentioned that the plastic hinges of STS are always preferred when designing efficient timber connections since these ductile failure modes provide a safe forcedisplacement response featured by a plateau after reaching the ultimate force.

Regarding the SSJ specimens retrofitted according to the first strategy (R1), the single and double plastic hinges of Fully Threaded Screws (FTS) implemented in the rafter have been observed, as illustrated in Figure 9 and Table 5. Since the stiffness of the front-notch surface is higher than that from the bottom-notch connection retrofitted with FTS, the maximal 
compressive strength of the former or the maximal shear strength in the tie beam can be reached before the maximal load-bearing capacity $R_{V, b o t t}$ does (Figure 3 ). Therefore, the plastic hinges of FTS may be not fully achieved after ending the monotonic compression tests. Another explanation may come from the late appearance of shear row splitting in the rafter, which slows down the yielding of FTS. Although it causes minor damage in the rafter, the shear row splitting should nevertheless be prevented or delayed as much as possible in order to avoid any reduction of the ultimate force in the rafter and provide better the ductile force-displacement response. In addition to the crushing at the front-notch surface, the shear crack may emerge in the tie beam as the final failure mode in the retrofitted SSJ specimens, causing the drop of the normal load in the rafter after reaching the ultimate force. In fact, the shear crack may occur for the SSJ specimens if the tie beam has not been retrofitted with Partly Threaded Screws (PTS) beforehand as shown in Figure 10.

As a reminder, the shear crack in the tie beam is a brittle failure mode leading to the collapse of the SSJ and thus the whole timber truss. By recovering from the shear crack, the second strategy (R2) also provides a ductile behaviour to the retrofitted SSJ specimens, thanks to the emergence of plastic hinges within STS, as given in Table 5. It should be stated that only single plastic hinges have been noticed for the PTS in the tie beam while single and double plastic hinges illustrated in Figure 11 arise for the FTS in the rafter. Being featured by high deformation of the joint according to maximal normal loads in the rafter, ductile failures will always be appreciated for their safety when retrofitting existing timber trusses. Nevertheless, the shear row splitting shown in Figure 12 may occur as a rushed brittle failure mode in the upper part of the tie beam along the PTS rows, resulting in reducing the ultimate normal force in the rafter. During the ductile post-peak response, the shear row splitting also appears in the rafter along the FTS rows, featuring greater damage than those observed for the SSJ specimens retrofitted as per the first strategy (R1).

Since it causes irreversible damage in both tie beam and rafter, the shear row splitting must then be carefully prevented by checking the geometrical recommendations about minimum 
spacing and distance of STS in respect with the minimum thickness of timber joint elements (Eurocode 5 (2004), Uibel et al. (2010), ETA-11/0030 (2012)). In the case where these recommendations are not met, the SSJ retrofitting with STS as per both strategies R1 and R2 could be considered as an irreversible intervention technique, entering into conflict with the restoration principles (Yeomans (2003), Croatto et al. (2014)). Nonetheless, the shear row splitting might still occur even if those geometrical recommendations are checked, since the front-notch surface is highly stressed in compression at the rafter and tie beam sides due to the significant rafter thrust for the SSJ characterized by low rafter skew angles $\beta_{\text {rafter }} \leq 45^{\circ}$.

\subsection{Performance of retrofitting strategies}

From the experimental results, the mechanical behaviour (i.e. ultimate force, stiffness, forcedisplacement response, and failure modes) has been compared, between the specimens of Single Step Joint (SSJ) retrofitted with Self-Tapping Screws (STS) and the initial ones from Verbist et al. (2017). Based on these interpretations, the performances of two different retrofitting strategies R1 and R2 can be discussed in the present research.

The first retrofitting strategy (R1) with Fully Threaded Screws (FTS) in the rafter is very efficient for the SSJ damaged due to the crushing at the front-notch surface. Indeed, it provides much higher ultimate normal loads in the rafter, in addition to a ductile mechanical behaviour through the yielding of FTS. However, the shear crack may occur as the final failure mode at the heel depth $t_{v}$ in the tie beam due to high crushing of the grain at the front-notch surface (Verbist et al. (2017)). Although the shear crack entails the drop of the normal load in the rafter, the retrofitted SSJ does not collapse thanks to the presence of FTS in the rafter. Nevertheless, the shear crack should be prevented by implementing beforehand Partly Threaded Screws (PTS) perpendicularly to the grain in the tie beam, alike the second retrofitting strategy (R2) shown in Figure 4.

By implementing PTS in the tie beam and FTS in the rafter, the second retrofitting strategy (R2) for the SSJ damaged due to the shear crack is efficient because it enables to reach easily 
the ultimate forces from the initial SSJ specimens. Similar to the first retrofitting strategy (R1), the ductile mechanical behaviour is also ensured through the yielding of PTS and FTS, but it is not optimal due to the early appearance of shear row splitting in the tie beam followed by the rafter. In order to investigate the impact of shear row splitting on the ductile force-displacement response from SSJ specimens retrofitted with STS, the geometrical recommendations (Eurocode 5 (2004), Uibel et al. (2010), ETA-11/0030 (2012)) about the minimum spacing and distance of STS in respect with the minimum thickness of timber joint elements have not been checked properly. Hence, the shear row splitting always occurs in the tie beam retrofitted with PTS due to the small thickness of the upper part, which is conditioned by the heel depth $t_{v}$ as illustrated in Figure 4.

Because the shear row splitting causes the decrease of the ultimate normal force in the rafter as well as irreversible damage in the timber joint elements, both retrofitting strategies R1 and R2 may enter into conflict with restoration principles. In order to guarantee the reversibility of these retrofitting strategies, the shear row splitting should be prevented through a balanced compromise between the mechanical performances of the SSJ retrofitted with STS and the geometrical recommendations about the STS positioning. Nonetheless, the impact of the shear row splitting on the mechanical behaviour of the SSJ retrofitted with STS is an interesting study which should warn off engineers when intervening in existing timber trusses including the presence of natural damage such as the shrinkage splitting. For instance, the shear row splitting is more likely to occur in both tie beam and rafter featuring any drying cracks, when retrofitting the SSJ with STS on-site, although the geometrical recommendations on the spacing and distances between screws are checked.

On the other hand, the stiffness of the retrofitted SSJ has dropped when comparing with those from the initial ones. If the SSJ retrofitted with STS is subject to significant normal loads in the rafter, high deformation of the connection may then occur with added 
eccentricity forces within the whole timber truss, leading to the reduction of their mechanical performances.

\section{Conclusion}

When assessing the Single Step Joint (SSJ) in existing timber roof structures, two types of structural damage (namely failure modes) can be encountered: (i) Crushing at the frontnotch surface; (ii) Shear crack in the tie beam. Being a recent technique commonly used in timber engineering for new buildings construction, the Self-Tapping Screws (STS) have then been selected to retrofit the SSJ damaged due to both failure modes. By taking into account the restoration principles and the mechanical performances of STS within timber-to-timber connections in single shear, two retrofitting strategies have been proposed in the Experimental Campaign. Afterwards, several damaged SSJ specimens have been retrofitted as per both strategies and then tested under monotonic compression in the rafter. By comparing the mechanical behaviour (i.e. ultimate force, stiffness, force-displacement response, and failure modes) between the retrofitted SSJ specimens and the initial ones from Verbist et al. (2017), the performances of both retrofitting strategies with STS have been discussed.

It has been concluded that both retrofitting strategies R1 and R2 are efficient since they provide higher rafter load-bearing capacities as well as a ductile post-peak response thanks to the yielding of STS implemented in the rafter and tie beam. Because the shear crack may still occur as the final failure mode for the SSJ retrofitted according to the first strategy R1, this brittle failure mode should then be prevented by positioning added STS perpendicularly to the grain in the tie beam, alike the second retrofitting strategy R2. Nonetheless, the stiffness of SSJ specimens retrofitted in respect with both strategies is lower than those of the initial ones. As a result, higher deformation in the retrofitted SSJ may then occur with 
added eccentricity forces within the whole timber truss, which leads to the reduction of their mechanical performances.

Furthermore, the shear row splitting may occur in the tie beam and rafter for the sound SSJ retrofitted as per both strategies if the geometrical recommendations on the spacing and distance between STS are not checked. Meanwhile, this failure mode might still emerge for the retrofitted SSJ featuring by natural damage such as drying cracks in the tie beam and rafter, which can often be noticed in the assessment of existing timber trusses, even if those geometrical recommendations are met. Since the shear row splitting causes severe damage in the timber joint elements, both retrofitting strategies with STS may become an irreversible intervention technique by entering into conflict with the restoration principles. In order to prevent the shear row splitting, a compromise should be found between the recommended minimum spacing of STS and the optimal load-bearing capacity from the retrofitted SSJ. The predrilled holes could also be a good alternative to stunt the emergence of the shear row splitting.

Although both retrofitting strategies R1 and R2 are efficient, they should be improved by considering better the restoration principles, especially the reversibility of the intervention technique. If future experimental contributions aims at performing a greater amount of retrofitted SSJ specimens for some geometrical configurations and at establishing reliable design models afterwards, both strategies R1 and R2 can then be used to retrofit with STS the SSJ damaged due to the crushing and shear crack. As prevention measures against both failure modes when designing new timber trusses, some strategies for the SSJ reinforcement with STS should also be investigated in the future, based on the retrofitting strategies R1 and R2 developed for the damaged SSJ in the present paper. 


\section{Acknowledgements}

This work was financed by FEDER funds through the Competitively Factors Operational Programme COMPETE and by national funds through FCT - Foundation for Science and Technology within the scope of the research projects INVISIBLE WOODS PTDC/EPH-PAT/2401/2014, PROTIMBER PTDC/ECM-EST/1072/2014, and the PhD Scholarships SFRH/BD/128580/2017.

\section{References}

Blass, H. J., Bejtka, I. (2002). Joints with inclined screws. - International Council for research and Innovation in Building and Construction - Working Commission W18, Timber Structures, CIB-W 18/35-7-5 - Kyoto, Japan, September 2002.

Bléron, L., Lathuillière, D., Descamps, T., Bocquet, J-F. (2015). Reinforcement of connections with dowel-type fasteners - Reinforcement of Timber Structures, A state-of-art report - Edited by Harte A. and Dietsch P. - Shaker Verlag Aachen, 2015.

Branco, J.M., Descamps, T. (2015). Analysis and strengthening of carpentry joints - Construction and Building Materials - Volume 97, 30 October 2015, Pages 34-47. Special Issue: Reinforcement of Timber Structures.

Croatto, G., Turrini, U. (2014). Restoration of historical timber structures - Criteria, innovative solutions and case studies - Seminário Intervenir em construções existentes de madeira Universidade do Minho - Lourenço, P.B., Branco, J.M., Sousa, H.S. (eds.).

Descamps, T., Avez, C., Carpentier, O., Antczak, E., Jeong, G.Y. (2016). Historic timber roofs modelling: prosthesis and resin repairs - Journal of Heritage Conservation - Volume 47, 2016, Pages 52-60.

Dietsch, P., Reinhard, B. (2015). Reinforcement with self-tapping screws and threaded rods Reinforcement of Timber Structures, A state-of-art report - Edited by Harte A. and Dietsch P. Shaker Verlag Aachen, 2015.

ETA-11/0030, European Technical Approval (2012). Self-tapping screws for use in timber structures EOTA (European Organization for Technical Approval) - Rotho Blaas Self-tapping Screws, 2012.

Eurocode 5, NBN EN 1995-1-1 (2004). Design of timber structures - Part 1-1: General - Common rules and rules for buildings - CEN, European Standardization Institute - Brussels, Belgium, November 2004.

Görlacher, R., Kromer, M (1991). Tragfähigkeit von Versatzanschlüssen in historischen Holzkonstruktionen - Bruderverlag, Karlsruhe, Germany - Edited by Bauen Mit Holz - March 1991. 
Munafò, P., Stazi, F., Tassi, C., Davi, F. (2015). Experimentation on historic timber trusses to identify repair techniques compliant with the original structural-constructive conception - Construction and Building Materials - Volume 87, July 2015, Pages 54-66.

Parisi, M.A., Piazza, M. (2000). Mechanics of plain and retrofitted traditional timber connections. Journal of Structural Engineering: ASCE, 126(12), 1395-1403.

Shupe, T., Lebow, S., Ring, D. (2008). Causes and control of wood decay, degradation and stain. LSU AgCenter - Research \& Extension. Louisiana State University Agriculture Center, Baton Rouge, LA. Publication 2703. 27 Pages. https://www.fpl.fs.fed.us/documnts/pdf2008/fpl_2008_shupe001.pdf Sobra, K., de Rijk, R., Aktas, Y.D., Avez, C., Burawska, I., Branco, J.M. (2016). Experimental and Analytical Assessment of the Capacity of Traditional Single Notch Joints and Impact of Retrofitting by Self-Tapping Screws. Historical Earthquake-Resistant Timber Framing in the Mediterranean Area. August 2016, Pages 359-369.

Tampone, G., Ruggieri, N. (2016). State-of-the-art technology on conservation of ancient roofs with timber structure. Journal of Cultural Heritage: Volume 22, November-December 2016, Pages 1019-1027.

Teles, C.D.M., Do Valle, A. (2001). Wood structures: Acting before deterioration. Historical Constructions. Lourenço, P.B., Roca, P. (Eds.). Guimarães, Portugal, 2001. Pages 857-866.

Tomasi R., Crosatti A., Piazza M. (2010). Theoretical and experimental analysis of timber-to-timber joints connected with inclined screws. Construction and Building Materials: Volume 24, Issue 9, Pages 1560-1571 - September 2010.

Uibel,T., Blass, H. J. (2010). A New Method to Determine Suitable Spacings and Distances for Selftapping Screws. International Council for research and Innovation in Building and Construction Working Commission W18, Timber Structures. New Zealand, August 2010.

Valentin, J-L. (2009). La charpente, mode d'emploi - Chantiers pratiques. Edition Eyrolles, deuxième tirage, 2009.

Verbist, M., Branco, J.M., Poletti, E., Descamps, T., Lourenço, P. (2017). Single Step Joint: overview of European standardized approaches and experimentations. Materials and Structures. DOI 10.1617/s11527-017-1028-4 - March 27, 2017.

Yeomans D. (2003). The Repair of Historic Timber Structures - Thomas Telford Ltd, London. 


\section{List of Figures}

Fig. 1 Geometrical parameters and failure modes of the Single Step Joint, modified from Verbist et al. (2017).

Fig. 2 Configuration of two STS typologies within timber-to-timber connections in single shear.

Fig. 3 First retrofitting strategy with STS (R1) for the SSJ damaged due to the crushing, and subsequent failure modes.

Fig. 4 Second retrofitting strategy with STS (R2) for the SSJ damaged due to the shear crack.

Fig. 5 Setup and LVDT's position during the monotonic compression tests in the rafter of the retrofitted SSJ specimens.

Fig. 6 Normal load in the rafter $\left(N_{\text {rafter }}\right)$ according to the displacement of the front-notch surface. Comparison between the initial SSJ specimens $45^{\circ}$ tv30_240SL and the retrofitted ones with STS (R1) against the crushing.

Fig. 7 Normal load in the rafter ( $\left.N_{\text {rafter }}\right)$ according to the displacement of the front-notch surface. Comparison between the initial SSJ specimens $30^{\circ}$ tv30_160SL and the retrofitted ones with STS (R2) against the shear crack.

Fig. 8 Normal load in the rafter ( $\left.N_{\text {rafter }}\right)$ according to the displacement of the front-notch surface. Comparison between the initial SSJ specimens GCPTB_30 $30^{\circ}$ and the retrofitted ones with STS (R2) against the shear crack.

Fig. 9 Double plastic hinges of FTS implemented in the rafter at the bottom-notch surface.

Fig. 10 Shear crack at the heel depth along the grain in the tie beam.

Fig. 11 Plastic hinges of FTS implemented in the rafter at the bottom-notch surface.

Fig. 12 Shear row splitting in the upper part of the tie beam retrofitted with PTS.

\section{List of Tables}

Table 1 Labelling, geometrical parameters (Figure 1) and failure modes of initial SSJ specimens from Verbist et al. (2017).

Table 2 STS implementation for the first retrofitting strategy (R1) in the SSJ specimens damaged due to the crushing (Figure 3).

Table 3 STS implementation for the second retrofitting strategy (R2) in the SSJ specimens damaged due to the shear crack (Figure 4).

Table 4 Comparison of ultimate forces and stiffness between the initial SSJ specimens and retrofitted ones with STS.

Table 5 Overall failure modes of the retrofitted SSJ specimens and local failure modes of STS implemented inside the tie beam and rafter. 


\section{Figures:}

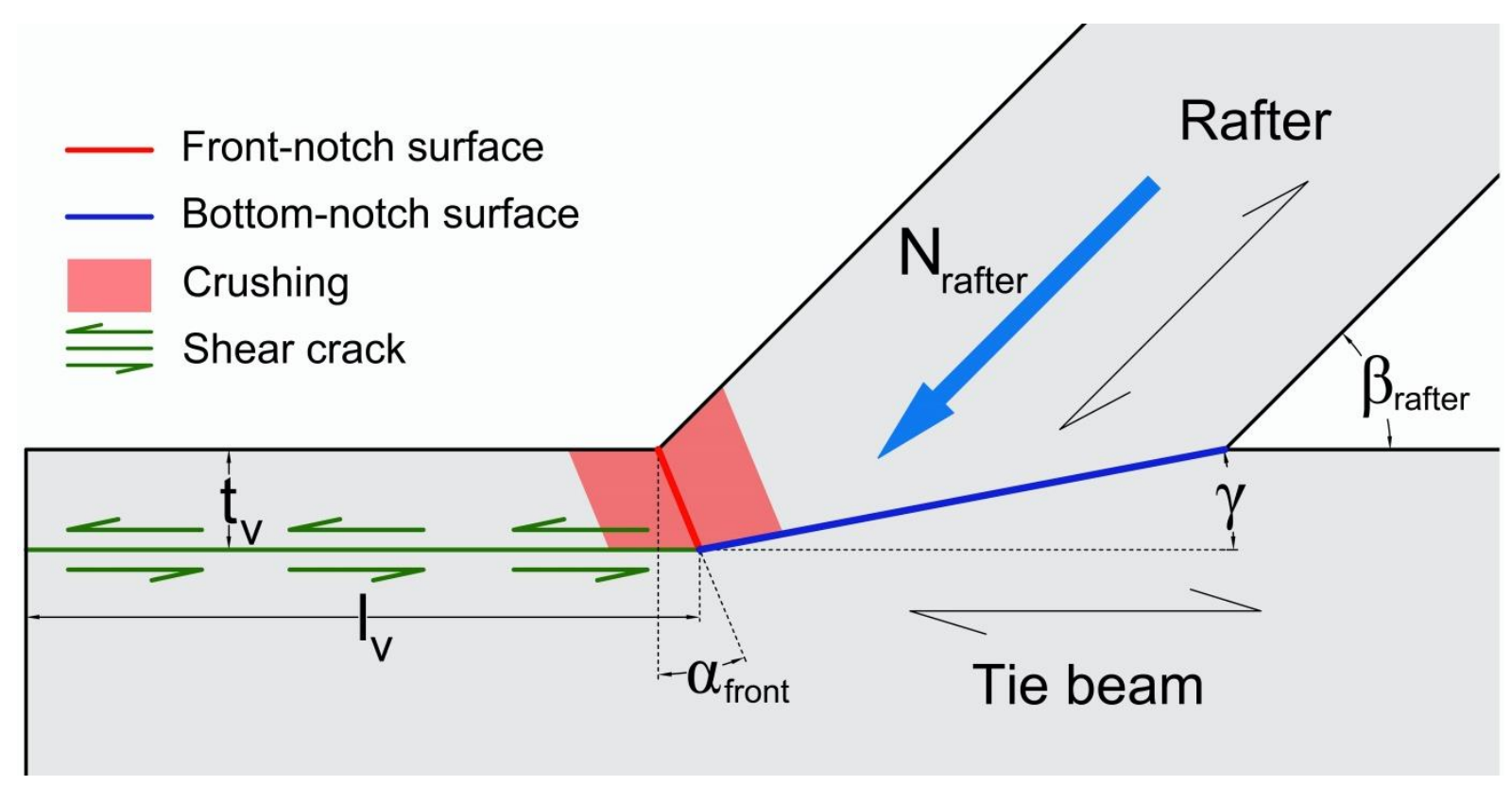

Fig. 1 Geometrical parameters and failure modes of the Single Step Joint, modified from Verbist et al. (2017).

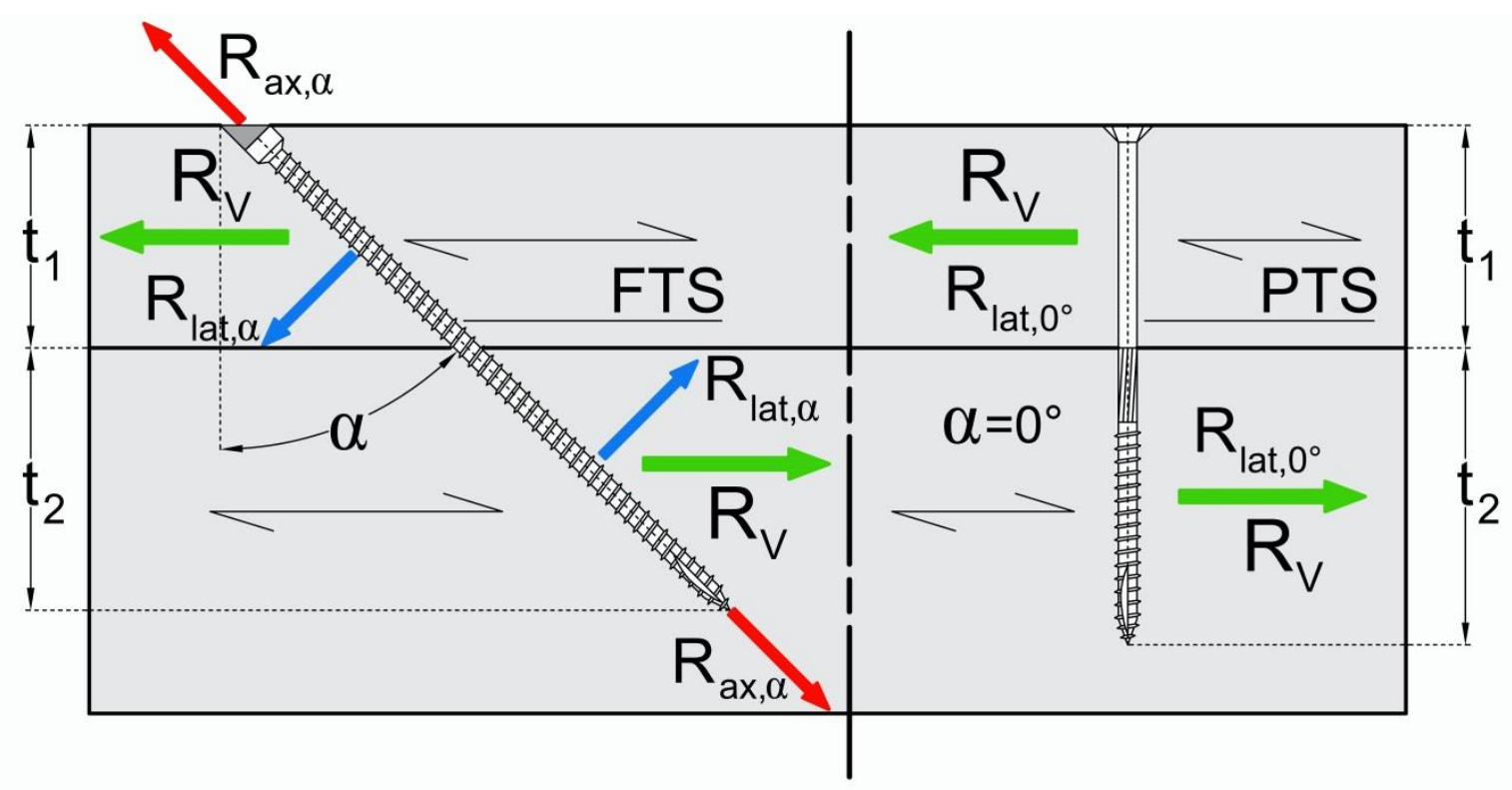

Fig. 2 Configuration of two STS typologies within timber-to-timber connections in single shear. 


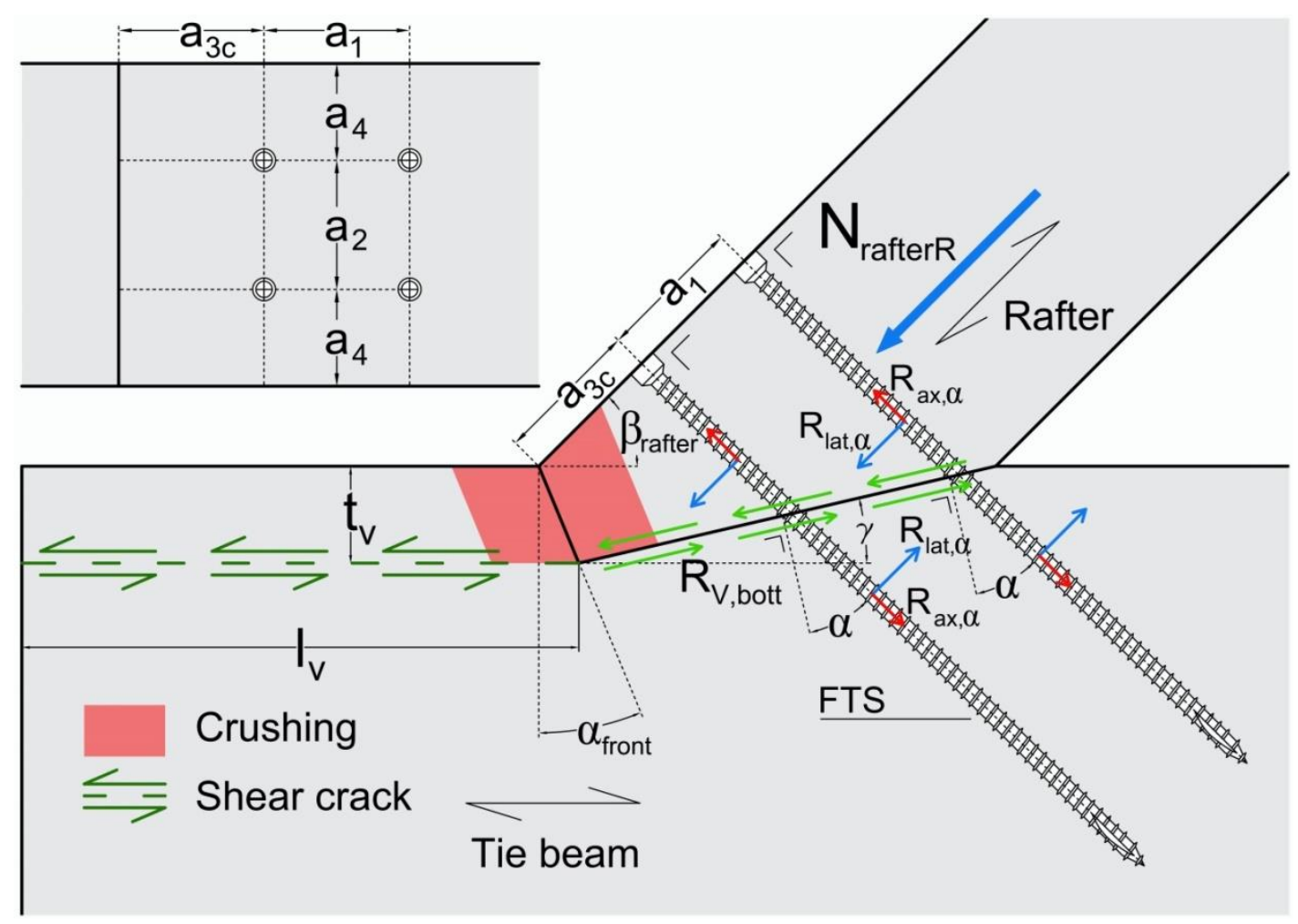

Fig. 3 First retrofitting strategy with STS (R1) for the SSJ damaged due to the crushing, and subsequent failure modes.

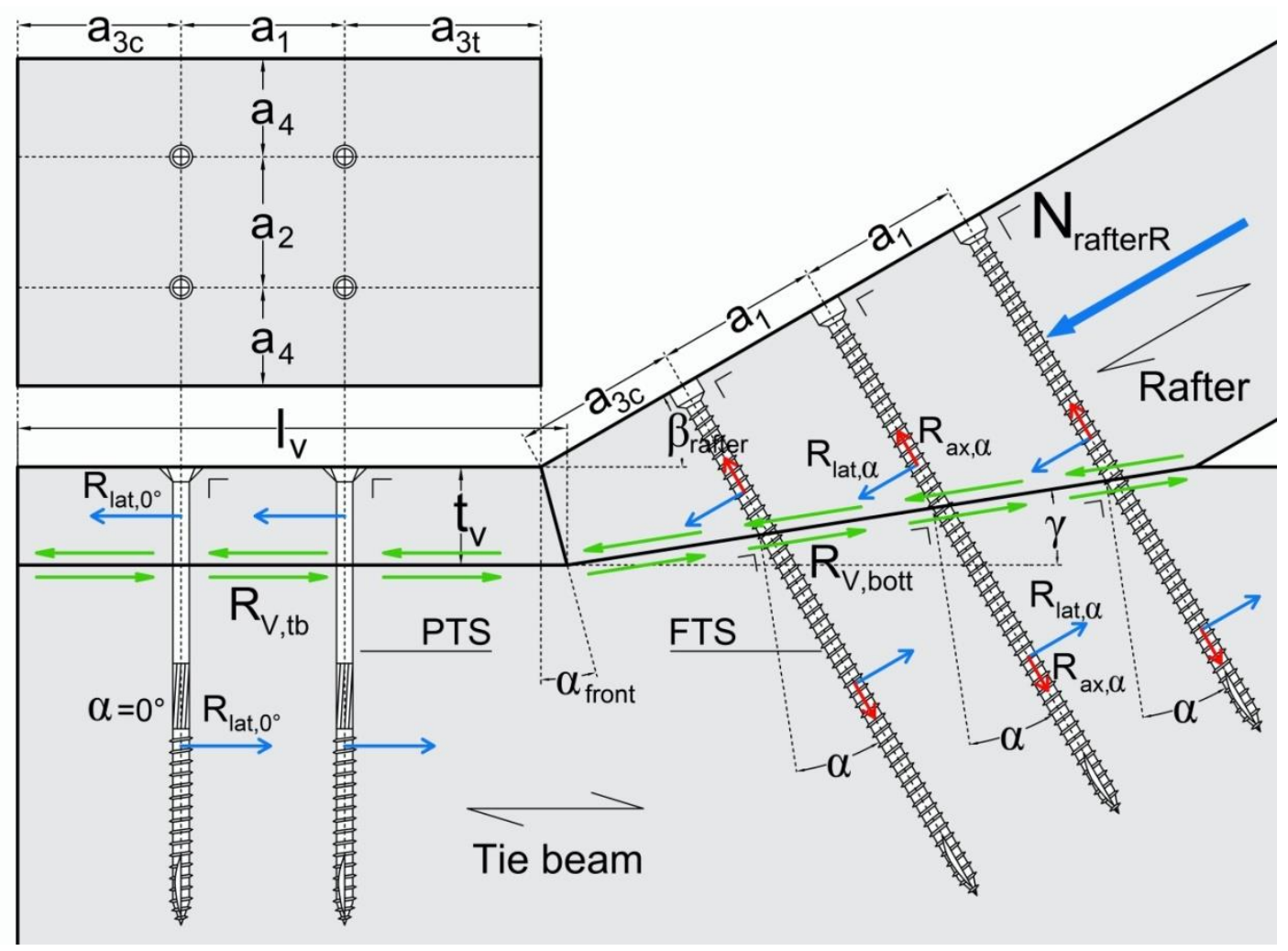

Fig. 4 Second retrofitting strategy with STS (R2) for the SSJ damaged due to the shear crack. 


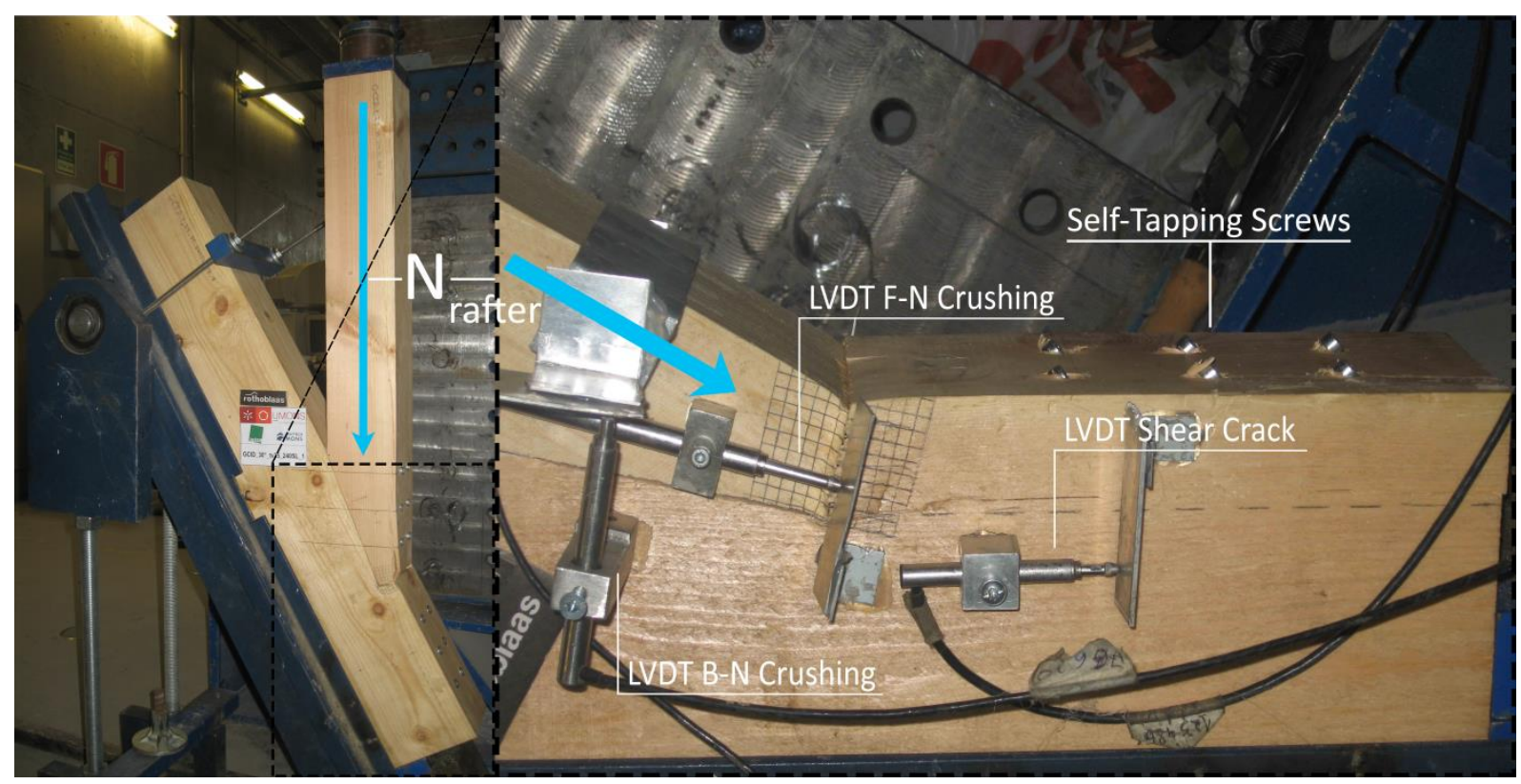

Fig. 5 Setup and LVDT's position during the monotonic compression tests in the rafter of the retrofitted SSJ specimens.

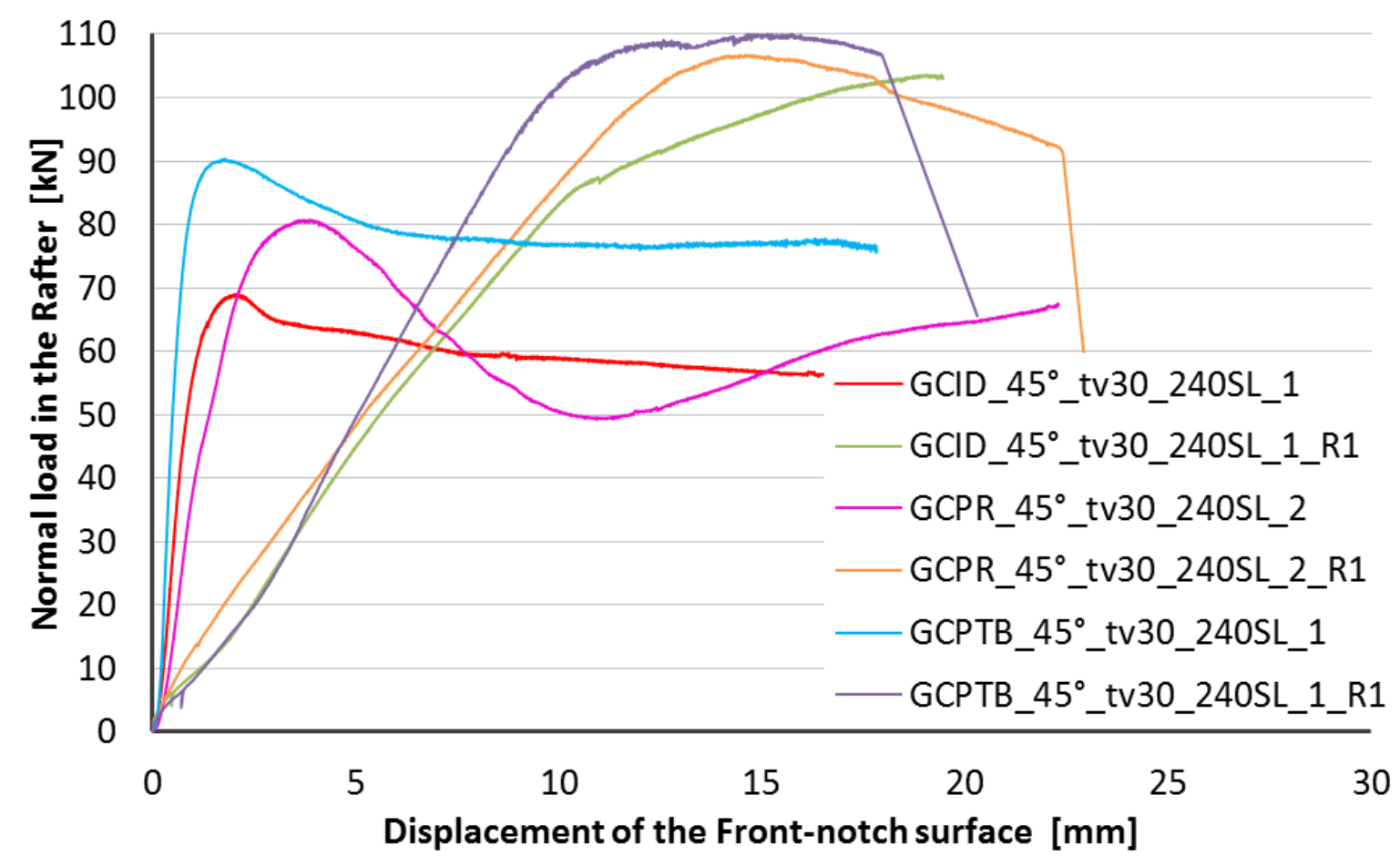

Fig. 6 Normal load in the rafter $\left(N_{\text {rafter }}\right)$ according to the displacement of the front-notch surface. Comparison between the initial SSJ specimens $45^{\circ}$ _tv30_240SL and the retrofitted ones with STS (R1) against the crushing. 


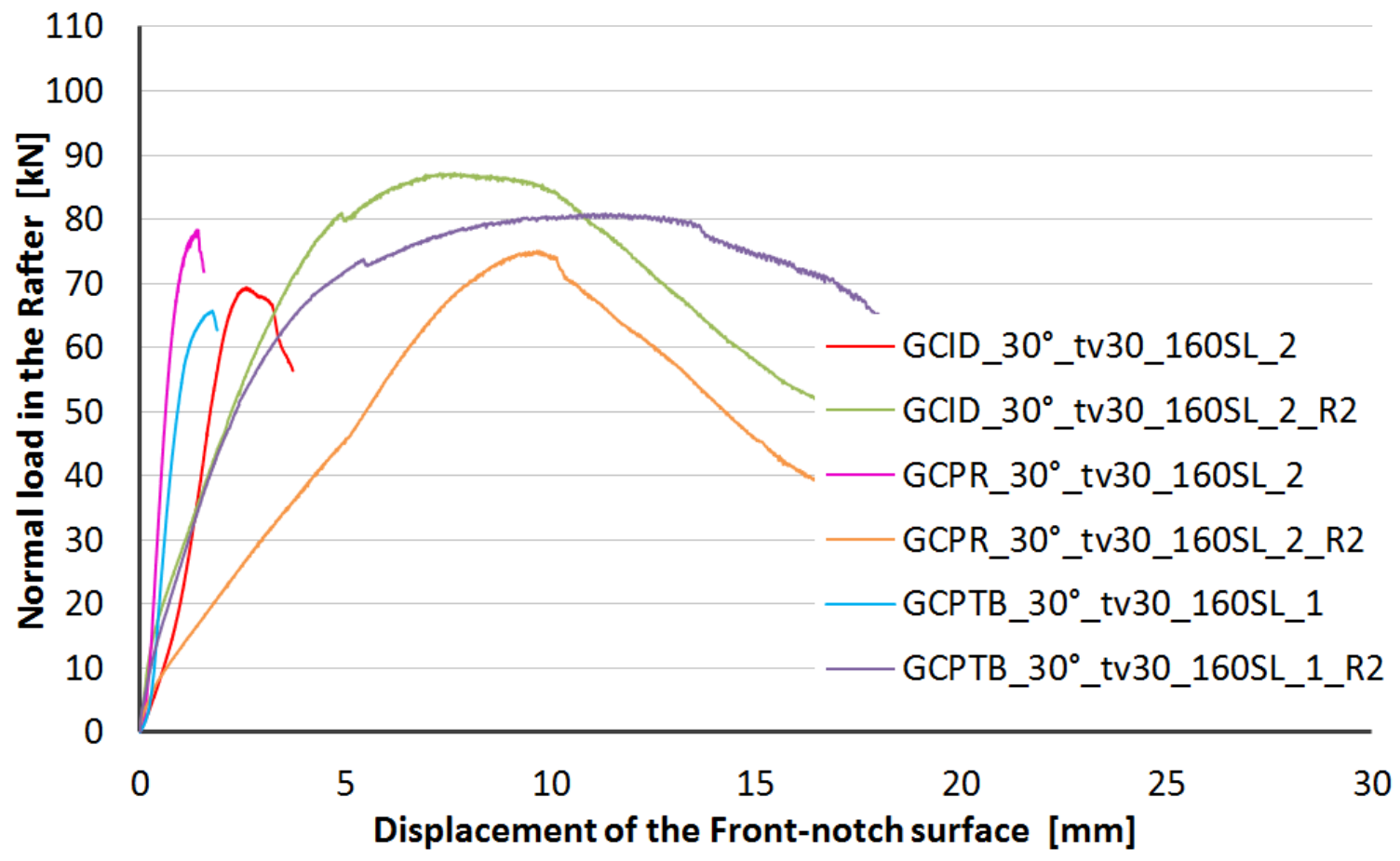

Fig. 7 Normal load in the rafter $\left(N_{\text {rafter }}\right)$ according to the displacement of the front-notch surface. Comparison between the initial SSJ specimens $30^{\circ}$ tv30_160SL and the retrofitted ones with STS (R2) against the shear crack.

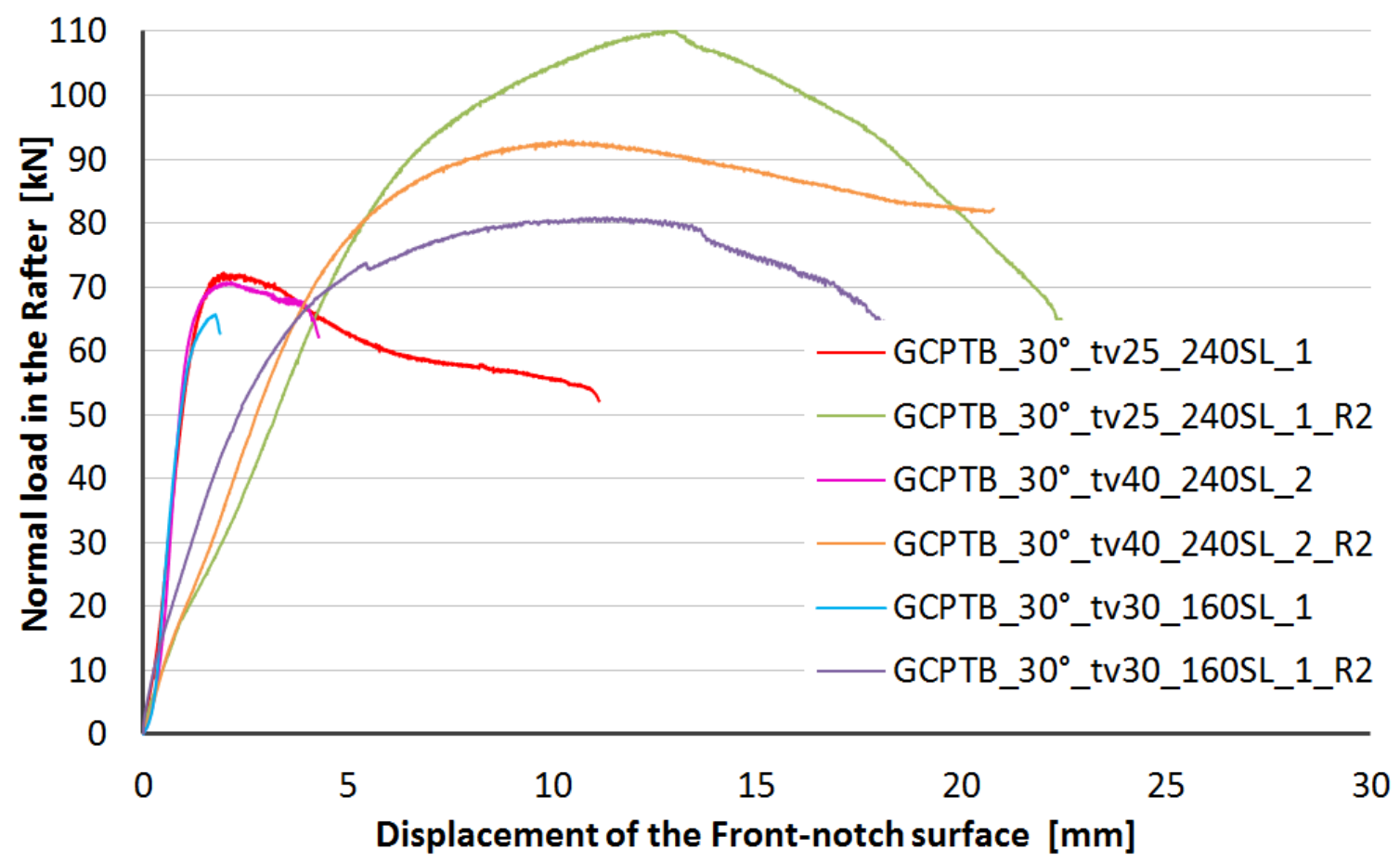

Fig. 8 Normal load in the rafter $\left(N_{\text {rafter }}\right)$ according to the displacement of the front-notch surface. Comparison between the initial SSJ specimens GCPTB_30 $30^{\circ}$ and the retrofitted ones with STS (R2) against the shear crack. 


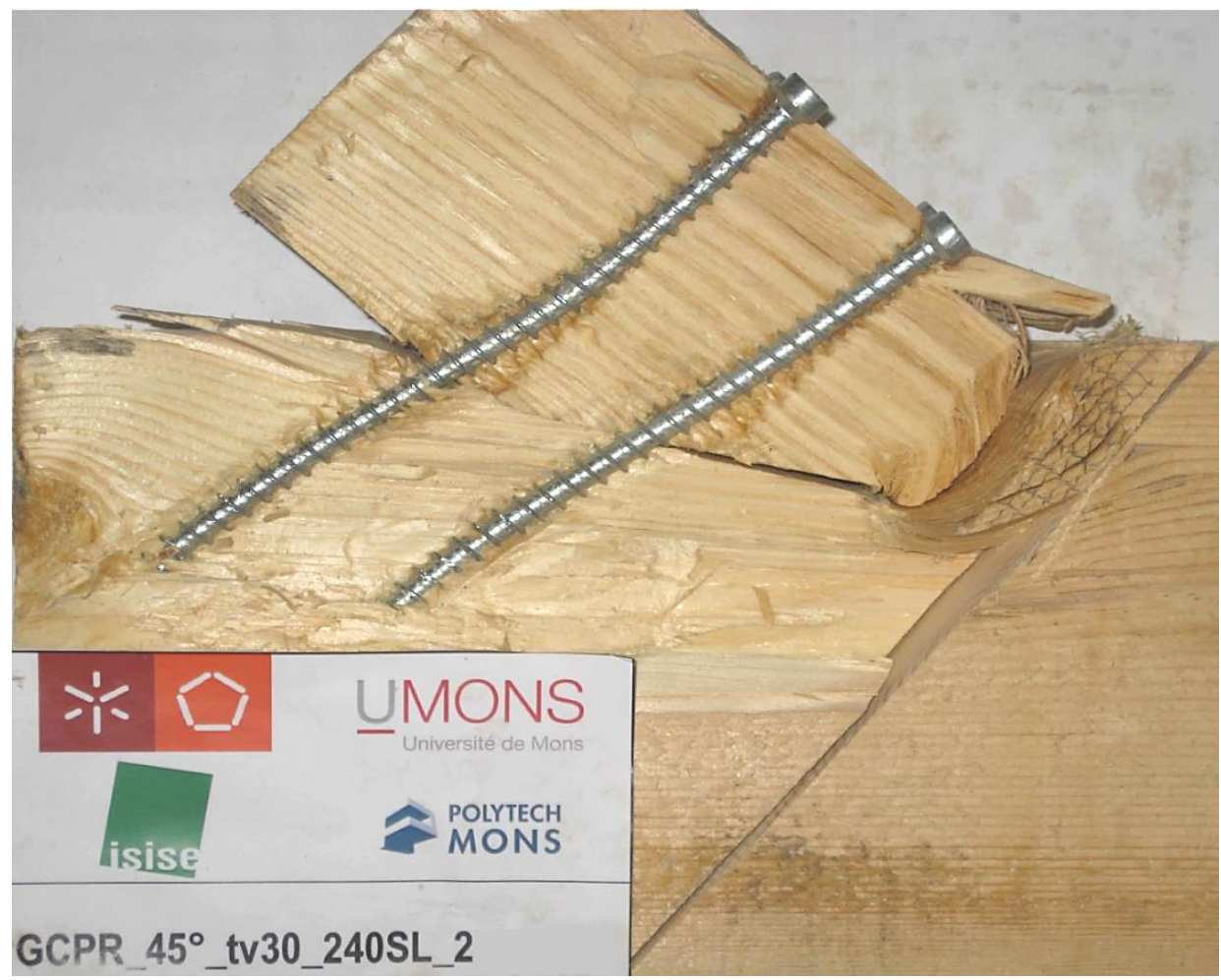

Fig. 9 Double plastic hinges of FTS implemented in the rafter at the bottom-notch surface.

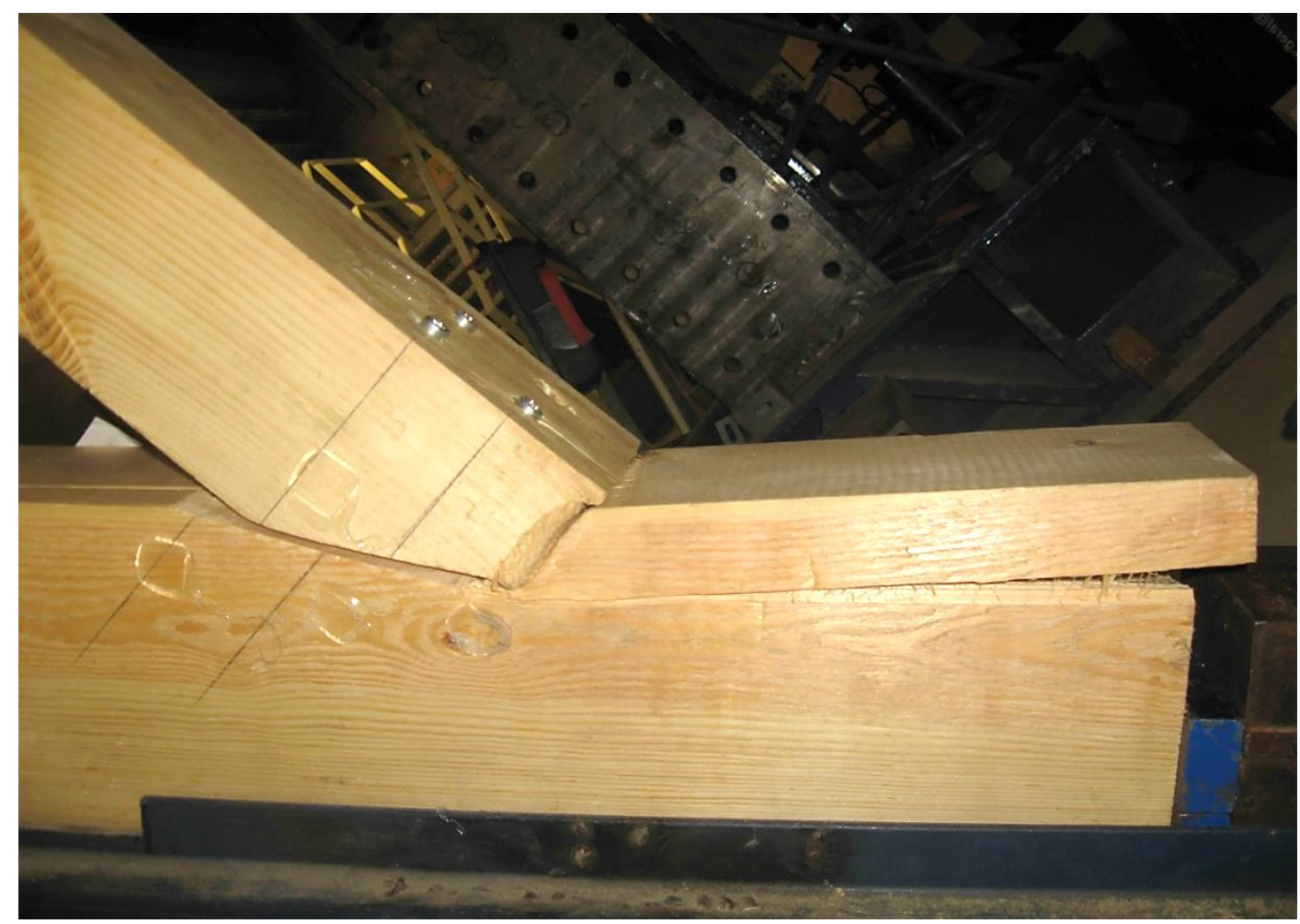

Fig. 10 Shear crack at the heel depth along the grain in the tie beam. 


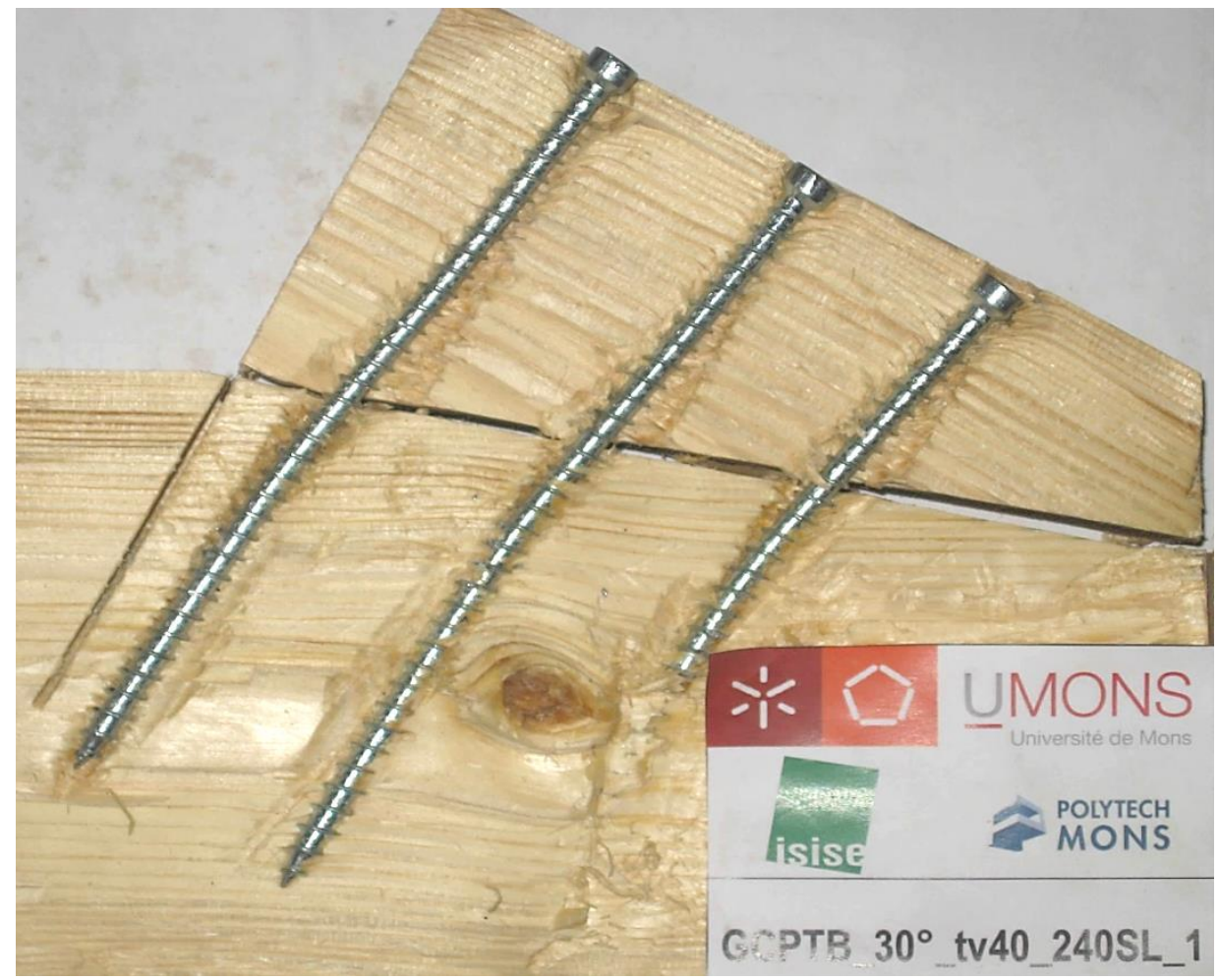

Fig. 11 Plastic hinges of FTS implemented in the rafter at the bottom-notch surface.

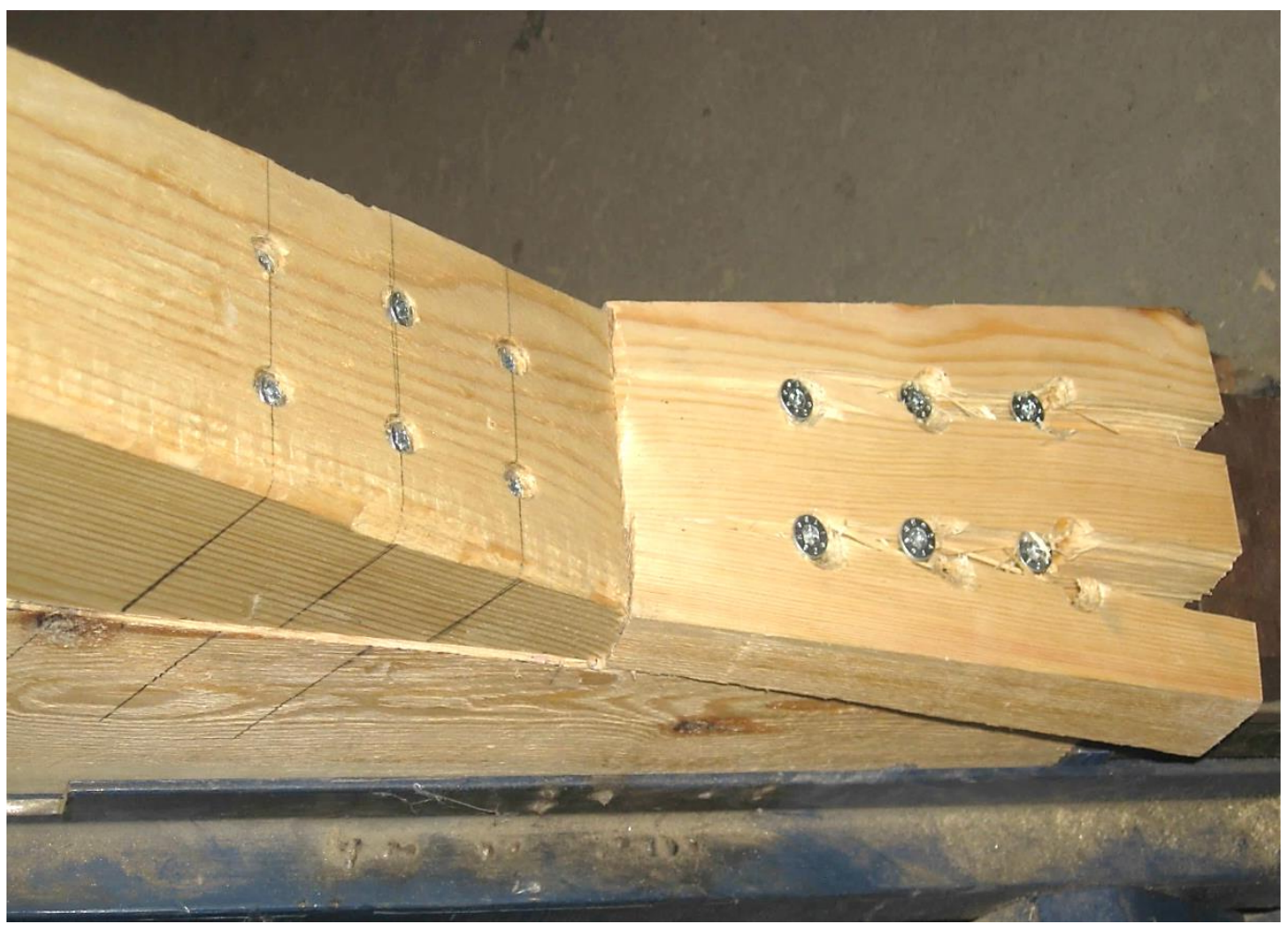

Fig. 12 Shear row splitting in the upper part of the tie beam retrofitted with PTS. 


\section{Tables:}

Table 1 Labelling, geometrical parameters (Fig. 1) and failure modes of initial SSJ specimens from Verbist et al. (2017).

\begin{tabular}{|c|c|c|c|c|c|}
\hline Specimen labelling & $\begin{array}{c}\alpha_{\text {front }} \\
{\left[{ }^{\circ}\right]}\end{array}$ & $\begin{array}{c}\beta_{\text {rafter }} \\
{\left[{ }^{\circ}\right]}\end{array}$ & $\begin{array}{c}t_{v} \\
{[\mathrm{~mm}]}\end{array}$ & $\begin{array}{c}l_{v} \\
{[\mathrm{~mm}]}\end{array}$ & $\begin{array}{l}\text { Failure } \\
\text { modes }\end{array}$ \\
\hline GCID_30 _tv25_240SL_1 & 15 & 30 & 25 & 240 & SC \\
\hline GCID_30 _tv25_240SL_2 & 15 & 30 & 25 & 240 & CFN \\
\hline GCID_30ttv30_160SL_1 & 15 & 30 & 30 & 160 & SC \\
\hline GCID_30 ${ }^{\circ}$ tv30_160SL_2 & 15 & 30 & 30 & 160 & SC \\
\hline GCID_30 ${ }^{\circ}$ tv30_240SL_1 & 15 & 30 & 30 & 240 & CFN \\
\hline GCID_30 $0^{\circ} \mathrm{tv} 30 \_240 \mathrm{SL} \_2$ & 15 & 30 & 30 & 240 & CFN \\
\hline GCID_45 ${ }^{\circ}$ tv30_240SL_1 & 22.5 & 45 & 30 & 240 & CFN \\
\hline $\mathrm{GCID} 45^{\circ} \_\mathrm{tv} 30 \_240 \mathrm{SL} \_2$ & 22.5 & 45 & 30 & 240 & CFN \\
\hline GCPR_30 ${ }^{\circ}$ tv25_240SL_1 & 30 & 30 & 25 & 240 & CFN \\
\hline GCPR_30 _tv25_240SL_2 & 30 & 30 & 25 & 240 & CFN \\
\hline GCPR_30 ${ }^{\circ}$ tv30_160SL_1 & 30 & 30 & 30 & 160 & SC \\
\hline GCPR_30 ${ }^{\circ}$ tv30_160SL_2 & 30 & 30 & 30 & 160 & SC \\
\hline GCPR_30 _tv30_240SL_1 & 30 & 30 & 30 & 240 & CFN \\
\hline GCPR_30 ${ }^{\circ}$ tv30_240SL_2 & 30 & 30 & 30 & 240 & SC \\
\hline GCPR_30 ${ }^{\circ}$ tv40_240SL_1 & 30 & 30 & 40 & 240 & CFN \\
\hline GCPR_30 ${ }^{\circ}$ tv40_240SL_2 & 30 & 30 & 40 & 240 & SC \\
\hline GCPR_45 _tv30_240SL_1 & 45 & 45 & 30 & 240 & SC \\
\hline GCPR_45 _tv30_240SL_2 & 45 & 45 & 30 & 240 & CFN \\
\hline GCPTB_30 _tv25_240SL_1 & 0 & 30 & 25 & 240 & SC \\
\hline GCPTB_30 _tv25_240SL_2 & 0 & 30 & 25 & 240 & SC \\
\hline GCPTB_30_tv30_160SL_1 & 0 & 30 & 30 & 160 & SC \\
\hline GCPTB_30 _tv30_160SL_2 & 0 & 30 & 30 & 160 & SC \\
\hline GCPTB_30tv40_240SL_1 & 0 & 30 & 40 & 240 & SC \\
\hline GCPTB_30 _tv40_240SL_2 & 0 & 30 & 40 & 240 & SC \\
\hline GCPTB_45﹎tv30_240SL_1 & 0 & 45 & 30 & 240 & CFN \\
\hline GCPTB_45﹎tv30_240SL_2 & 0 & 45 & 30 & 240 & CFN \\
\hline
\end{tabular}

Legend:

GCID - Geometrical Configuration Ideal Design; GCPR - Geometrical Configuration Perpendicular to the Rafter; GCPTB - Geometrical Configuration Perpendicular to the Tie beam; $\alpha_{\text {front }}-$ Inclination angle of the front-notch surface; $\beta_{\text {rafter }}-$ Rafter skew angle; $t_{v}$ - Heel depth; $l_{v}$ - Shear length; CFN Crushing at the front-notch surface; SC - Shear crack in the tie beam. 
Table 2 STS implementation for the first retrofitting strategy (R1) in the SSJ specimens damaged due to the crushing (Fig. 3).

\begin{tabular}{|c|c|c|c|c|c|c|}
\hline \multirow{2}{*}{$\begin{array}{c}\text { Specimen labelling } \\
\text { GCID_30﹎tv25_240SL_2 }\end{array}$} & \multicolumn{2}{|c|}{$\begin{array}{l}\text { STS inventory in } \\
\text { the SSJ elements }\end{array}$} & \multirow{2}{*}{$\frac{\begin{array}{c}a_{1} \\
{[\mathrm{~mm}]}\end{array}}{50}$} & \multirow{2}{*}{$\begin{array}{c}\begin{array}{c}a_{2} \\
{[\mathrm{~mm}]}\end{array} \\
40\end{array}$} & \multirow{2}{*}{$\frac{\begin{array}{c}a_{3, c} \\
{[\mathrm{~mm}]}\end{array}}{50}$} & \multirow{2}{*}{$\begin{array}{c}\begin{array}{c}a_{4} \\
{[\mathrm{~mm}]}\end{array} \\
30\end{array}$} \\
\hline & Rafter & $6 \times$ FTS & & & & \\
\hline GCID_30 _tv30_240SL_1 & Rafter & $6 \times$ FTS & 50 & 40 & 50 & 30 \\
\hline GCID_30 _tv30_240SL_2 & Rafter & $6 \times$ FTS & 50 & 40 & 50 & 30 \\
\hline GCID_45﹎tv30_240SL_1 & Rafter & $4 \times$ FTS & 45 & 40 & 45 & 30 \\
\hline GCID_45﹎tv30_240SL_2 & Rafter & $4 \times$ FTS & 45 & 40 & 45 & 30 \\
\hline GCPR_30 $0^{\circ} t \mathrm{tv} 25 \_240 \mathrm{SL} \_1$ & Rafter & $6 \times$ FTS & 50 & 40 & 50 & 30 \\
\hline GCPR_30 ${ }^{\circ}$ tv25_240SL_2 & Rafter & $6 \times$ FTS & 50 & 40 & 50 & 30 \\
\hline GCPR_30 ${ }^{\circ}$ tv30_240SL_1 & Rafter & $6 \times$ FTS & 50 & 40 & 50 & 30 \\
\hline GCPR_30 ${ }^{\circ}$ tv40_240SL_1 & Rafter & $6 \times$ FTS & 50 & 40 & 50 & 30 \\
\hline GCPR_45 ${ }^{\circ}$ tv30_240SL_2 & Rafter & $4 \times$ FTS & 45 & 40 & 45 & 30 \\
\hline GCPTB_45﹎tv30_240SL_1 & Rafter & $4 \times$ FTS & 45 & 40 & 45 & 30 \\
\hline GCPTB_45ㅇ_tv30_240SL_2 & Rafter & $4 \times$ FTS & 45 & 40 & 45 & 30 \\
\hline
\end{tabular}

Legend:

FTS - Fully Threaded Screws; PTS - Partly Threaded Screws; $a_{1}$ - Spacing, parallel to the grain, of screws within one row; $a_{2}$ - Spacing, perpendicular to the grain, between rows of screws; $a_{3, c}-$ Distance between screw and unloaded end of the SSJ element; $a_{4}$ - Distance between screw and edge of the SSJ element. 
Table 3 STS implementation for the second retrofitting strategy (R2) in the SSJ specimens damaged due to the shear crack (Fig. 4).

\begin{tabular}{|c|c|c|c|c|c|c|c|}
\hline Specimen labelling & \multicolumn{2}{|c|}{$\begin{array}{l}\text { STS inventory in } \\
\text { the SSJ elements }\end{array}$} & $\begin{array}{c}a_{1} \\
{[\mathrm{~mm}]}\end{array}$ & $\begin{array}{c}a_{2} \\
{[\mathrm{~mm}]}\end{array}$ & $\begin{array}{c}a_{3, c} \\
{[\mathrm{~mm}]}\end{array}$ & $\begin{array}{c}a_{3, t} \\
{[\mathrm{~mm}]}\end{array}$ & $\begin{array}{c}a_{4} \\
{[\mathrm{~mm}]}\end{array}$ \\
\hline \multirow{2}{*}{ GCID_30_tv25_240SL_1 } & Tie beam & $6 \times$ PTS & 50 & 40 & 70 & 70 & 30 \\
\hline & Rafter & $6 \times$ FTS & 50 & 40 & 50 & ------ & 30 \\
\hline \multirow{2}{*}{ GCID_30﹎tv30_160SL_1 } & Tie beam & $4 \times$ PTS & 50 & 40 & 50 & 60 & 30 \\
\hline & Rafter & $6 \times$ FTS & 50 & 40 & 50 & ------ & 30 \\
\hline \multirow{2}{*}{ GCID_30ttv30_160SL_2 } & Tie beam & $4 \times$ PTS & 50 & 40 & 50 & 60 & 30 \\
\hline & Rafter & $6 \times$ FTS & 50 & 40 & 50 & ------ & 30 \\
\hline \multirow{2}{*}{ GCPR_30 _tv30_160SL_1 } & Tie beam & $4 \times$ PTS & 50 & 40 & 50 & 60 & 30 \\
\hline & Rafter & $6 \times$ FTS & 50 & 40 & 50 & ------ & 30 \\
\hline \multirow{2}{*}{ GCPR_30﹎tv30_160SL_2 } & Tie beam & $4 \times$ PTS & 50 & 40 & 50 & 60 & 30 \\
\hline & Rafter & $6 \times$ FTS & 50 & 40 & 50 & ------ & 30 \\
\hline \multirow{2}{*}{ GCPR_30﹎tv30_240SL_2 } & Tie beam & $6 \times$ PTS & 50 & 40 & 70 & 70 & 30 \\
\hline & Rafter & $6 \times$ FTS & 50 & 40 & 50 & ------ & 30 \\
\hline \multirow{2}{*}{ GCPR_30﹎tv40_240SL_2 } & Tie beam & $6 \times$ PTS & 50 & 40 & 70 & 70 & 30 \\
\hline & Rafter & $6 \times$ FTS & 50 & 40 & 50 & ------ & 30 \\
\hline \multirow{2}{*}{ GCPR_45ㄴttv30_240SL_1 } & Tie beam & $6 \times$ PTS & 50 & 40 & 70 & 70 & 30 \\
\hline & Rafter & $4 \times$ FTS & 45 & 40 & 45 & ----- & 30 \\
\hline \multirow{2}{*}{ GCPTB_30﹎tv25_240SL_1 } & Tie beam & $6 \times$ PTS & 50 & 40 & 70 & 70 & 30 \\
\hline & Rafter & $6 \times$ FTS & 50 & 40 & 50 & ------ & 30 \\
\hline \multirow{2}{*}{ GCPTB_30﹎tv25_240SL_2 } & Tie beam & $6 \times$ PTS & 50 & 40 & 70 & 70 & 30 \\
\hline & Rafter & $6 \times$ FTS & 50 & 40 & 50 & ------ & 30 \\
\hline \multirow{2}{*}{ GCPTB_30 _tv30_160SL_1 } & Tie beam & $4 \times$ PTS & 50 & 40 & 50 & 60 & 30 \\
\hline & Rafter & $6 \times$ FTS & 50 & 40 & 50 & ------ & 30 \\
\hline \multirow{2}{*}{ GCPTB_30﹎tv30_160SL_2 } & Tie beam & $4 \times$ PTS & 50 & 40 & 50 & 60 & 30 \\
\hline & Rafter & $6 \times$ FTS & 50 & 40 & 50 & ------ & 30 \\
\hline \multirow{2}{*}{ GCPTB_30﹎tv40_240SL_1 } & Tie beam & $6 \times$ PTS & 50 & 40 & 70 & 70 & 30 \\
\hline & Rafter & $6 \times$ FTS & 50 & 40 & 50 & ------ & 30 \\
\hline \multirow{2}{*}{ GCPTB_30﹎tv40_240SL_2 } & Tie beam & $6 \times$ PTS & 50 & 40 & 70 & 70 & 30 \\
\hline & Rafter & $6 \times$ FTS & 50 & 40 & 50 & ------ & 30 \\
\hline
\end{tabular}

Legend:

FTS - Fully Threaded Screws; PTS - Partly Threaded Screws; $a_{1}$ - Spacing, parallel to the grain, of screws within one row; $a_{2}$ - Spacing, perpendicular to the grain, between rows of screws; $a_{3, c}-$ Distance between screw and unloaded end of the SSJ element; $a_{3, t}$ - Distance between screw and loaded end of the SSJ element; $a_{4}$ - Distance between screw and edge of the SSJ element. 
Table 4 Comparison of ultimate forces and stiffness between the initial SSJ specimens and retrofitted ones with STS.

\begin{tabular}{|c|c|c|c|c|c|c|}
\hline Specimen labelling & $\begin{array}{c}\mathrm{N}_{\text {rafterR }} \\
{[\mathrm{kN}]}\end{array}$ & $\begin{array}{c}\mathrm{N}_{\text {rafter }} \\
{[\mathrm{kN}]}\end{array}$ & $\begin{array}{c}\Delta_{r e l, N} \\
{[\%]} \\
\end{array}$ & $\begin{array}{c}K_{F N, R} \\
{[\mathrm{kN} / \mathrm{mm}]}\end{array}$ & $\begin{array}{c}K_{F N} \\
{[\mathrm{kN} / \mathrm{mm}]}\end{array}$ & $\begin{array}{c}\Delta_{r e l, K} \\
{[\%]} \\
\end{array}$ \\
\hline GCID_30tv25_240SL_1_R2 & 105 & 55 & 91 & 17 & 26 & -35 \\
\hline GCID_30﹎tv25_240SL_2_R1 & 130 & 65 & 100 & 16 & 26 & -38 \\
\hline GCID_30_tv30_160SL_1_R2 & 102 & 78 & 31 & 15 & 50 & -70 \\
\hline GCID_30_tv30_160SL_2_R2 & 87 & 69 & 26 & 15 & 26 & -42 \\
\hline GCID_30﹎tv30_240SL_1_R1 & 120 & 53 & 126 & 8 & 26 & -69 \\
\hline GCID_30tv30_240SL_2_R1 & 130 & 69 & 88 & 9 & 33 & -73 \\
\hline GCID_45﹎tv30_240SL_1_R1 & 103 & 69 & 49 & 8 & 34 & -76 \\
\hline GCID_45﹎tv30_240SL_2_R1 & 92 & 83 & 11 & 11 & 41 & -73 \\
\hline GCPR_30_tv25_240SL_1_R1 & 108 & 59 & 83 & 13 & 22 & -41 \\
\hline GCPR_30﹎tv25_240SL_2_R1 & 130 & 54 & 141 & 9 & 28 & -68 \\
\hline GCPR_30﹎tv30_160SL_1_R2 & 90 & 60 & 50 & 14 & 86 & -84 \\
\hline GCPR_30﹎tv30_160SL_2_R2 & 74 & 78 & -5 & 9 & 33 & -73 \\
\hline GCPR_30ttv30_240SL_1_R1 & 126 & 88 & 43 & 16 & 61 & -74 \\
\hline GCPR_30tv30_240SL_2_R2 & 76 & 91 & -16 & 17 & 47 & -64 \\
\hline GCPR_30﹎tv40_240SL_1_R1 & 133 & 93 & 43 & 16 & 42 & -62 \\
\hline GCPR_30﹎tv40_240SL_2_R2 & 88 & 79 & 11 & 16 & 65 & -75 \\
\hline GCPR_45﹎tv30_240SL_1_R2 & 100 & 96 & 4 & 14 & 90 & -84 \\
\hline GCPR_45﹎tv30_240SL_2_R1 & 106 & 80 & 32 & 8 & 32 & -75 \\
\hline GCPTB_30 _tv25_240SL_1_R2 & 109 & 72 & 51 & 13 & 52 & -75 \\
\hline GCPTB_30﹎tv25_240SL_2_R2 & 102 & 64 & 59 & 19 & 33 & -42 \\
\hline GCPTB_30_tv30_160SL_1_R2 & 80 & 65 & 23 & 20 & 57 & -65 \\
\hline GCPTB_30 _tv30_160SL_2_R2 & 85 & 70 & 21 & 20 & 86 & -77 \\
\hline GCPTB_30_tv40_240SL_1_R2 & 90 & 82 & 10 & 11 & 89 & -88 \\
\hline GCPTB_30 _tv40_240SL_2_R2 & 92 & 70 & 31 & 17 & 60 & -72 \\
\hline GCPTB_45﹎tv30_240SL_1_R1 & 109 & 90 & 21 & 12 & 89 & -86 \\
\hline GCPTB_45﹎tv30_240SL_2_R1 & 110 & 69 & 59 & 11 & 54 & -80 \\
\hline
\end{tabular}

Legend:

R1 - First retrofitting strategy (Figure 3); R2 - Second retrofitting strategy (Figure 4); $\mathrm{N}_{\text {rafterR }}$ Ultimate normal force in the rafter from retrofitted SSJ specimens; $\mathrm{N}_{\text {rafter }}$ - Ultimate normal force in the rafter from initial SSJ specimens; $\Delta_{r e l, N}$ - Relative variation of ultimate normal forces in the rafter between the initial SSJ specimens and the retrofitted ones with STS; $K_{F N, R}$ - Stiffness at the frontnotch surface from retrofitted SSJ specimens; $K_{F N}$ - Stiffness at the front-notch surface from initial SSJ specimens; $\Delta_{r e l, K}-$ Relative variation of the stiffness at the front-notch surfaces between the initial SSJ specimens and the retrofitted ones with STS. 
Table 5 Overall failure modes of the retrofitted SSJ specimens and local failure modes of STS implemented inside the tie beam and rafter.

\begin{tabular}{|c|c|c|c|c|c|}
\hline \multirow{2}{*}{ Specimen labelling } & \multirow{2}{*}{ Retrofitted SSJ } & \multicolumn{2}{|c|}{ Tie beam } & \multicolumn{2}{|c|}{ Rafter } \\
\hline & & $\mathrm{CE}$ & $\mathrm{SPH}$ & $\mathrm{SPH}$ & $\mathrm{DPH}$ \\
\hline GCID_30﹎tv25_240SL_1_R2 & SRS & $6 \times$ PTS & ------ & $6 \times$ FTS & ------ \\
\hline GCID_30tv25_240SL_2_R1 & SC / SRS & ------ & ------ & $6 \times$ FTS & ------ \\
\hline GCID_30_tv30_160SL_1_R2 & SRS & ------ & $4 \times$ PTS & $6 \times$ FTS & ------ \\
\hline GCID_30﹎tv30_160SL_2_R2 & SRS & ------ & $4 \times$ PTS & $6 \times$ FTS & ------ \\
\hline GCID_30﹎tv30_240SL_1_R1 & SC & ----- & ----- & $2 \times$ FTS & $4 \times$ FTS \\
\hline GCID_30tv30_240SL_2_R1 & SC /SRS & ------ & ----- & $4 \times$ FTS & $2 \times$ FTS \\
\hline GCID_45﹎tv30_240SL_1_R1 & CFN / SRS & ------ & ------ & $2 \times$ FTS & $2 \times$ FTS \\
\hline GCID_45ㄴtv30_240SL_2_R1 & CFN / SRS & ------ & ------ & $2 \times$ FTS & $2 \times$ FTS \\
\hline GCPR_30﹎tv25_240SL_1_R1 & CFN /SRS & ------ & ------ & $4 \times$ FTS & $2 \times$ FTS \\
\hline GCPR_30﹎tv25_240SL_2_R1 & CFN & ----- & ----- & $4 \times$ FTS & $2 \times$ FTS \\
\hline GCPR_30﹎tv30_160SL_1_R2 & SRS & ------ & $4 \times$ PTS & $4 \times$ FTS & $2 \times$ FTS \\
\hline GCPR_30 _tv30_160SL_2_R2 & SRS & ------ & $4 \times$ PTS & $6 \times$ FTS & ------ \\
\hline GCPR_30﹎tv30_240SL_1_R1 & CFN /SRS & ------ & ------ & $4 \times$ FTS & $2 \times$ FTS \\
\hline GCPR_30 _tv30_240SL_2_R2 & SRS & ----- & $6 \times$ PTS & $4 \times$ FTS & $2 \times$ FTS \\
\hline GCPR_30﹎tv40_240SL_1_R1 & SC & ------ & ------ & $2 \times$ FTS & $4 \times$ FTS \\
\hline GCPR_30 _tv40_240SL_2_R2 & SRS & ------ & $6 \times$ PTS & $6 \times$ FTS & ------ \\
\hline GCPR_45﹎tv30_240SL_1_R2 & SRS & $6 \times$ PTS & ------ & $4 \times$ FTS & ------ \\
\hline GCPR_45﹎tv30_240SL_2_R1 & SC / SRS & ------ & ------ & $4 \times$ FTS & ------ \\
\hline GCPTB_30﹎tv25_240SL_1_R2 & SRS & ------ & $6 \times$ PTS & $4 \times$ FTS & $2 \times$ FTS \\
\hline GCPTB_30 _tv25_240SL_2_R2 & SRS & ------ & $6 \times$ PTS & $4 \times$ FTS & $2 \times$ FTS \\
\hline GCPTB_30 _tv30_160SL_1_R2 & SRS & ------ & $4 \times$ PTS & $6 \times$ FTS & ------ \\
\hline GCPTB_30 _tv30_160SL_2_R2 & SRS & ------ & $4 \times$ PTS & $6 \times$ FTS & ------ \\
\hline GCPTB_30 _tv40_240SL_1_R2 & SRS & ------ & $6 \times$ PTS & $4 \times$ FTS & $2 \times$ FTS \\
\hline GCPTB_30 _tv40_240SL_2_R2 & SRS & ------ & $6 \times$ PTS & $4 \times$ FTS & $2 \times$ FTS \\
\hline GCPTB_45﹎tv30_240SL_1_R1 & SC / SRS & ------ & ----- & $4 \times$ FTS & ----- \\
\hline GCPTB_45﹎tv30_240SL_2_R1 & CFN / SRS & ------ & ------ & $2 \times \mathrm{FTS}$ & $2 \times$ FTS \\
\hline
\end{tabular}

Legend:

R1 - First retrofitting strategy (Figure 3); R2 - Second retrofitting strategy (Figure 4); CFN - Crushing at the front-notch surface; SC - Shear Crack in the tie beam; SRS - Shear row splitting; FTS - Fully Threaded Screws; PTS - Partly Threaded Screws; CE - Crushing inside timber due to STS embedment; SPH - Single plastic hinge of STS; DPH - Double plastic hinge of STS. 